The Cryosphere Discuss., doi:10.5194/tc-2016-167, 2016

Manuscript under review for journal The Cryosphere

Published: 11 July 2016

(c) Author(s) 2016. CC-BY 3.0 License.

\title{
Strain localisation and dynamic recrystallisation in the ice-air aggregate: A numerical study
}

\author{
Florian Steinbach ${ }^{1,2}$, Paul D. Bons ${ }^{1}$, Albert Griera ${ }^{3}$, Daniela Jansen², Maria-Gema Llorens ${ }^{1}$, Jens \\ Roessiger $^{1}$, Ilka Weikusat ${ }^{1,2}$
}

$5 \quad{ }^{1}$ Department of Geosciences, Eberhard Karls University Tübingen, 72074 Tübingen, Germany

${ }^{2}$ Alfred Wegener Institute Helmholtz Centre for Polar and Marine Research, 27568 Bremerhaven, Germany

${ }^{3}$ Departament de Geologia, Universitat Autònoma de Barcelona, 08193 Bellaterra (Barcelona), Spain

Correspondence to: Florian Steinbach (florian.steinbach@uni-tuebingen.de)

Abstract. We performed numerical simulations on the micro-dynamics of ice with air inclusions as a second phase. This

10 provides first results of a numerical approach to model dynamic recrystallisation in polyphase crystalline aggregates. Our aim was to investigate the rheological effects of air inclusions and explain the onset of dynamic recrystallisation in the permeable firn. The simulations employ a full field theory crystal plasticity code coupled to codes simulating dynamic recrystallisation processes and predict time-resolved microstructure evolution in terms of lattice orientations, strain distribution, grain sizes and grain boundary network. Results show heterogeneous deformation throughout the simulations

15 and indicate the importance of strain localisation controlled by air inclusions. This strain localisation gives rise to locally increased energies that drive dynamic recrystallisation and induce heterogeneous microstructures that are coherent with natural firn microstructures from EPICA Dronning Maud Land ice coring site in Antarctica. We conclude that although overall strains and stresses in firn are low, strain localisation associated with locally increased strain energies can explain the occurrence of dynamic recrystallisation.

\section{Introduction}

The ice sheets on Greenland and Antarctica are composed of snow layers, originally containing a large proportion of air, which are transformed into solid ice due to compaction and sintering processes (Herron and Langway, 1980; Colbeck, 1983). At the firn-ice transition, the air is sealed off in bubbles as the pores are no longer connected and do not allow exchange with air from other layers or the atmosphere (Schwandner and Stauffer, 1984; Stauffer et al., 1985). For this reason, the ice sheets are considered as valuable archives of the paleo-atmosphere (Luethi et al., 2008; Fischer et al., 2008). However, ice sheets are not static, but flow under their own weight, which can potentially cause the paleo-climatic record to lose its integrity (Faria et al., 2010). For the interpretation of these records it is essential to not only understand the deformation dynamics of polycrystalline ice, but also the implications of a second phase in the form of air bubbles. For consistency, we use the expression air bubbles whenever referring to the natural material and air inclusion only for numerical models, where the individual units of air are neither interconnected, nor communicating. 
The Cryosphere Discuss., doi:10.5194/tc-2016-167, 2016

Manuscript under review for journal The Cryosphere

Published: 11 July 2016

(c) Author(s) 2016. CC-BY 3.0 License.

Compared to other abundant minerals on the surface, ice on earth is always at very high homologous temperatures $\left(T_{h}=\right.$ $T_{\text {actual }} / T_{\text {meltpoint }}$ ), close to its pressure melting point and therefore creeping under gravitational forces (Petrenko and Whitworth, 1999; Faria et al. 2014a). The macroscopic behaviour of the ice aggregate results from the local response of individual ice crystals and the distribution of second phases within the polycrystalline aggregate.

5 Deformation in the ice crystal is mainly accommodated by dislocations, meaning intracrystalline lattice defects gliding and climbing through the crystal lattice, which is known as dislocation creep (Shoji and Higashi, 1978; Schulson and Duval, 2009; Faria et al. 2014b). Ice Ih is the ice polymorph that occurs on Earth. It has a hexagonal symmetry and dislocation glide is primarily on planes perpendicular to the c-axes (i.e. basal planes) or on pyramidal or prismatic planes. Dislocation glide in ice Ih is characterized by a strong visco-plastic anisotropy, with resistance to glide on basal planes at least 60 times smaller

10 than on other planes (Duval et al., 1983). The strong preference for basal glide usually leads to an approximately single maximum crystallographic preferred orientation (CPO) with the c-axes mostly aligned with the direction of maximum finite shortening (Azuma and Higashi, 1985). Such a single-maximum CPO causes a mechanical anisotropy of a deformed aggregate of ice grains (Budd and Jacka, 1989; Treverrow et al., 2012).

Visco-plastic deformation of ice is accompanied by recrystallisation (Duval, 1979; Jacka and Li, 1994; Faria et al. 2014b), as

15 is common in minerals at high homologous temperatures. According to Duval et al. (2000), recrystallisation processes have direct implications on creep behaviour as they affect fabric development and hence the flow of ice (Montagnat et al., 2011). The nomenclature to describe recrystallisation and microstructure varies between glaciology, geology and material science. For consistency, in this manuscript we employ the terminology proposed by Faria et al. (2014b).

Under static conditions and non-deformation related, normal grain growth or static grain boundary migration driven by

20 surface energy minimisation (Stephenson, 1967; Gow, 1969; Duval, 1985) leads to a microstructure with only slightly curved grain boundaries and $120^{\circ}$ angles at grain triple junctions (foam texture). The resulting grain size distribution is lognormal according to (Humphreys and Hatherly, 2004, pp. 334-335). On the contrary, strain-induced boundary migration (SIBM) as described by Duval et al., (1983) or Humphreys and Hatherly (2004, pp. 251-253) minimizes stored strain energy by migrating boundaries towards less strained neighbouring grains. Intracrystalline annihilation of dislocations by lattice re25 orientation into lower energy configurations, known as recovery (White, 1977; Urai et al., 1986; Borthwick et al., 2014), additionally lowers stored strain energies. Recovery accompanied by gradual formation of subgrain boundaries and ultimately new high angle grain boundaries (e.g. polygonisation, Alley et al., 1995) is termed rotation recrystallisation (Passchier and Trouw, 2005). These recrystallisation phenomena operate during deformation are summarized by the term dynamic recrystallisation.

30 Recrystallisation processes operate concurrently, but the proportion of contribution of each mechanism varies. The dynamic recrystallisation diagram by Faria et al. (2014b) describes the relative contributions as a function of strain rate and temperature, as was done before for quartz (Hirth and Tullis, 1992). According to these models, rotation recrystallisation is more dominant with higher strain rates whereas strain-induced boundary migration dominates at higher temperatures. 
The Cryosphere Discuss., doi:10.5194/tc-2016-167, 2016

Manuscript under review for journal The Cryosphere

Published: 11 July 2016

(c) Author(s) 2016. CC-BY 3.0 License.

In very shallow firn, at mass densities below $550 \mathrm{~kg} \mathrm{~m}^{-3}$, compaction by displacement, re-arrangement and shape-change of snow particles is attributed to grain boundary sliding (Alley, 1987), neck growth between grains by isothermal sintering (Blackford, 2007) and temperature gradient metamorphism (Riche et al., 2013). Once the critical density is exceeded, the dominating mechanism becomes plastic deformation by intracrystalline creep (Anderson and Benson, 1963; Faria et al.,

5 2014b). For the EPICA Dronning Maud Land (EDML) ice core, this critical density is reached at around $20 \mathrm{~m}$ depth (Kipfstuhl et al., 2009). However, more recent tomographic analyses on EDML samples by Freitag et al. (2008) provide evidence for an early onset of plastic deformation at shallow depths of $10 \mathrm{~m}$. Simulations by Theile et al. (2011) suggest an even shallower onset of plastic deformation and the absence of grain boundary sliding.

One way to determine which deformation mechanisms operated is to study the microstructure of the deformed material

10 (Passchier and Trouw, 2005; Kipfstuhl et al., 2009; Faria et al., 2014a, b). Apart from experiments, numerical simulations are increasingly used as a tool to establish the link between deformation mechanisms, boundary conditions and resulting microstructures (see review of Montagnat et al., 2014). Unfortunately, most studies on ice deformation only considered pure ice without air bubbles. Some exceptions are the experimental studies of Arena et al. (1997) and Azuma et al. (2012), or the numerical simulations of Roessiger et al. (2014) on grain growth of ice in the presence of air inclusions. Systematic

15 numerical studies of the effect of a second phase, in this case air, on plastic deformation and dynamic recrystallisation are still lacking.

In this contribution we investigate the implications of air inclusions on deformation and recrystallisation to assess the importance of dynamic recrystallisation at shallow levels of ice sheets. For that purpose, we for the first time employ an explicit numerical approach combining both polyphase crystal plasticity and recrystallisation. Particular focus is given to two

20 microdynamical aspects, which are (1) the strain distribution in the polyphase and polycrystalline ice-air aggregate and (2) its relation to (deformation induced) dynamic recrystallisation.

\section{Methods}

\subsection{Multi-process modelling with Elle}

We used the open-source numerical modelling platform Elle (Bons et al., 2008; Jessell et al., 2001; Piazolo et al., 2010), as

25 this code is very suitable to model the interaction of multiple processes that act on a microstructure. So far, Elle has been applied to a range of microdynamic processes, such as strain localisation and porphyroclast rotation (Griera et al., 2011; 2013), deformation of polyphase materials (Jessell et al., 2009) or folding (Llorens et al., 2013a, b). Recent applications of methods also used in this study are on dynamic recrystallisation in pure ice (Llorens et al., 2016a, b), grain growth (Roessiger et al., 2011; 2014), and folding in ice sheets in relation to mechanical anisotropy, both on the small (Jansen et al., 30 2016) and large scale (Bons et al., 2016). To simulate visco-plastic deformation of the polyphase and polycrystalline aggregate with concurrent recrystallisation, the full field crystal visco-plasticity code VPFFT by Lebensohn (2001) was coupled to implementations of recrystallisation processes in Elle using the approach described in Llorens et al. (2016a, b). 
The Cryosphere Discuss., doi:10.5194/tc-2016-167, 2016

Manuscript under review for journal The Cryosphere

Published: 11 July 2016

(c) Author(s) 2016. CC-BY 3.0 License.

Here we only briefly explain the essentials of the modelling technique. The reader is referred to Jessell et al. (2001) and Bons et al. (2008) for the general principles of Elle. Details of the algorithms for grain boundary migration can be found in Becker et al. (2008) and Roessiger et al. (2011; 2014), and for coupled VPFFT and recrystallisation in Llorens et al. (2016a, b).

\section{$5 \quad 2.2$ Discretisation of the microstructure}

The two-dimensional microstructure of ice and air inclusions is discretised in a contiguous set of polygons with fully wrapping and periodic boundaries (Fig. 1a; Llorens et al., 2016a.b; Bons et al., 2008). In the setup used here, the polygons (termed flynns) are either ice crystals or air inclusions. Island grains such as a grain inside another grain are not allowed in Elle, for topological reasons. Flynns are delimited by straight segments that join boundary nodes (bnodes) in either double-

10 or triple-junctions. Quadruple or higher-order junctions are also not allowed in Elle. Additionally, we superimpose a regular grid of unconnected nodes (unodes) on the set of flynns. Unodes store local state variables such as stress, normalized von Mises strain rate or dislocation density. Crystallographic orientations at unodes are defined by Euler triplet angles, following the Bunge convention. After each deformation increment, all state variables are mapped back to a regular, rectangular unode grid, as this is required by the VPFFT code. To track the finite deformation, a second set of unodes, on an initially regular

15 square grid, represent material points or passive markers that are displaced each deformation step.

Topology checks are carried out at all times during a simulation to ensure compliance with topology restrictions and to maintain the set resolution. These include keeping bnode distances between a minimum and maximum separation by either deleting or inserting bnodes (Fig. 1b), and removing flynns that are smaller than a set minimum area or contain no unodes (Fig. 1c). To avoid the formation of a quadruple junction, a neighbour switch is performed between triple junctions closer

20 than the minimum separation distance (Fig. 1c). When two sides of a flynn approach each other to below a set minimum distance, the flynn is split into two (Fig. 1e). This allows bulging grain boundaries to sweep across entire grains without causing overlapping flynns.

\subsection{Visco-plastic deformation using full field approach}

The full field crystal visco-plasticity code (VPFFT) by Lebensohn (2001) was coupled to the Elle numerical modelling 25 platform following the approach by Griera et al. (2013) and Llorens et al. (2016a). The approach is based on calculating the mechanical field (i.e. stress, strain rate) from a kinematically admissible velocity field that minimizes the average local work-rate under the compatibility and equilibrium constraints (Lebensohn 2001; Lebensohn et al., 2009; Griera et al. 2013). In this approach, intracrystalline deformation is assumed to be accommodates by dislocation glide on pre-defined slip systems, using a non-linear viscous, rate-dependent law. The strain rate $\dot{\varepsilon}_{i j}(\boldsymbol{x})$ at each position $\boldsymbol{x}$ (unode-position) in the grid

30 is essentially the sum of the shear strain rates on all $N$ slip systems (Eq. 1): 
The Cryosphere Discuss., doi:10.5194/tc-2016-167, 2016

Manuscript under review for journal The Cryosphere

Published: 11 July 2016

(c) Author(s) 2016. CC-BY 3.0 License.

$\dot{\varepsilon}_{i j}(\boldsymbol{x})=\sum_{s=1}^{N} m_{i j}^{S}(\boldsymbol{x}) \dot{\gamma}^{s}(\boldsymbol{x})=\dot{\gamma}_{0} \sum_{s=1}^{N} m_{i j}^{s}(\boldsymbol{x})\left(\frac{m_{i j}^{s}(\boldsymbol{x}) \sigma_{i j}^{\prime}(\boldsymbol{x})}{\tau^{s}(\boldsymbol{x})}\right)^{3}$

The constitutive equation relates the shear rate $\dot{\gamma}^{s}$ on each slip system $(s)$, relative to a reference shear rate $\dot{\gamma}_{0}$, to the deviatoric stress $\sigma_{i j}^{\prime}$ and the orientation of the slip system that is defined by the symmetric Schmidt tensor $m_{i j}^{S}$ (the dyadic

product of a vector normal to the slip plane and slip direction). The effective viscosity or "ease of slip" of each slip system is defined by the slip-system dependent critical resolved shear stress $\tau^{s}$. Here we use a stress exponent of three, assuming Glen's law (Glen, 1958).

Since the strain rate and stress fields are initially unknown, an iterative scheme is implemented with a spectral solver using a Fast Fourier Transformation. The VPFFT code provides the full velocity field, which is integrated to the displacement field

10 for a small time step, assuming velocities remain constant. The displacement field is applied to the passive marker grid and to all bnodes to apply the deformation to the grains and air inclusions. Lattice orientations are updated and remapped onto the rectangular unode grid. Furthermore, geometrically necessary dislocation densities are calculated using the plastic strain gradient following Brinckmann et al. (2006) and assuming constant Burgers vectors for all slip systems.

\subsection{Recrystallisation}

\section{$15 \quad$ 2.4.1 Polyphase grain boundary migration}

Polyphase grain boundary migration is modelled using a front-tracking approach, which is explained in detail by Becker et al. (2008) and Llorens et al. (2016a). Grain boundary migration is achieved by moving individual bnodes. In general, the movement $\Delta x$ of a bnode is calculated from its mobility $M$ and driving force $S$ over a small numerical time step $\Delta t$ :

$\Delta x=\operatorname{SM}\left(M_{0}, T\left({ }^{\circ} \mathrm{C}\right)\right) \Delta t$

where the mobility $M$ is a function of temperature $T$ and intrinsic mobility $M_{0}$ (Nasello et al. 2005). The intrinsic mobility $M_{0}$ varies for different phase boundaries. The driving force $S$ is calculated from the change in local free energy $(d E)$ resulting from a change in position $(d x)$ of the bnode under consideration. $d E$ is a function of the change in boundary length and, hence, total local grain-boundary surface energy (Becker et al. 2008) and the change in stored strain energy (Llorens et al.

25 2016). A bnode is moved (using Eq. 2) in the direction of maximum free-energy reduction, which is determined from four small orthogonal trial displacements of that bnode. For the movement of ice-air boundaries, the stored strain energy was not taken into account.

In a polyphase aggregate, the conservation of mass requirement influences boundary migration. In theory, any local movement of a boundary needs to conserve the cross sectional area of its host grain. This restriction would inhibit most ice-

30 air interface movements, prohibiting any geometrical changes of air inclusions. Therefore, an additional energy term $\left(E_{\text {area }}\right)$ is introduced to counter-act that the surface energy $\left(E_{\text {surf }}\right)$ would drive an ice-air boundary inwards and let air inclusions 
The Cryosphere Discuss., doi:10.5194/tc-2016-167, 2016

Manuscript under review for journal The Cryosphere

Published: 11 July 2016

(c) Author(s) 2016. CC-BY 3.0 License.

shrink (Roessiger et al., 2014). For ice-air boundaries, stored strain energy is not taking into account and the total local energy $\left(E_{\text {total }}\right)$ at a given trial position $j$ then depends on the relative area change resulting from a theoretical movement of the boundary node to this position:

$5 E_{\text {total }}(j)=E_{\text {surf }}(j)+E_{\text {area }}(j)$

$E_{\text {area }}(j)=c\left(\frac{A(j)-A_{0}}{A_{0}}\right)^{2}$

where $A_{j}$ is the area of the air inclusion when the bnode is at trial position $j$ and $A_{0}$ is the initial inclusion area. Decreasing $c$ essentially increases the accepted violation of the conservation of mass requirement, allowing a stronger change in cross

10 sectional area. For the polyphase aggregate of ice and air, the pre-factor $c$ can be regarded as a compressibility factor: Theoretically, surface energy drives the bubble surface inward, compressing the enclosed air and increasing the air pressure in the bubble. This pressure would counter-act the surface movement until an equilibrium between surface tension and inner bubble pressure is reached, leading to a stable bubble cross sectional area. The factor $c$ controls how quickly this equilibrium is reached.

15 Grain boundary mobility is a function of temperature and intrinsic boundary mobility. Following the results of Nasello et al. (2005), the intrinsic mobility $M_{\text {ice-ice }}$ of ice-ice boundaries was set to $0.023 \mathrm{~m}^{4} \mathrm{~J}^{-1} \mathrm{~s}^{-1}$ and their surface energy $\gamma_{\text {ice-ice }}$ to $0.065 \mathrm{~J}$ $\mathrm{m}^{-2}$ (Ketcham and Hobbs, 1969). Based on Roessiger et al. (2014), the mobility ratio of ice-ice and ice-air boundaries $M_{\text {ice- }}$ ${ }_{i c e} / M_{\text {ice-air }}$ was set to 10 and the surface energy $\gamma_{\text {ice-air }}$ of ice-air boundaries to $0.52 \mathrm{~J} \mathrm{~m}^{-2}$. This causes a dihedral angle of $173^{\circ}$ at ice-air triple junctions. For all simulations, $c$ was set to 0.1 .

20 In a two-phase model, such as ice with air inclusions, three boundary types are possible: Ice-ice, air-ice and air-air boundaries. Air-air boundaries can occur in the model, for example when two air inclusions merge into one. These boundaries are purely numerical and have no physical meaning. They are therefore excluded them from any modelling processes or post-processing analyses.

During the simulation, all bnodes are selected in a random order and moved according to Eq. (2) one at a time. After each movement, topological checks are performed in keeping with the topological restrictions of Elle and to avoid impossible topologies such as bnodes sweeping across other grain boundary segments. Once a unode is swept by a moving boundary and thus changes its host grain, its dislocation density is set to zero and its lattice orientation to the value of the nearest neighbour unode in the new host grain.

\subsubsection{Rotation recrystallisation}

30 The process of rotation recrystallisation is modelled in two separate steps during the multi-process simulation: (1) Recovery be rearranging the intracrystalline lattice orientations into lower energy configurations such as subgrain boundaries, which is 
The Cryosphere Discuss., doi:10.5194/tc-2016-167, 2016

Manuscript under review for journal The Cryosphere

Published: 11 July 2016

(c) Author(s) 2016. CC-BY 3.0 License.

the predecessor for (2) the creation of new grains defined by high angle boundaries, which here implies inserting new boundary nodes and splitting an existing flynn.

In analogy to the grain boundary migration code, an energy minimisation system is used. Each unode is regarded as a small crystallite characterized by a lattice misorientation with respect to its first-order neighbours. Misorientation is the difference

5 in lattice orientation between two unodes, which increases the total free energy of the local system. Small trial rotations are used to determine which lattice rotation would result in the maximum decrease in local free energy. The lattice in the unode is then rotated according to this decrease and a "mobility" term, as described in detail in Borthwick et al. (2014) and Llorens et al. (2016a).

Both the visco-plastic deformation and the above recovery process lead to polygonisation, i.e. the formation of new high-

10 angle grain boundaries defined by a lattice misorientation between neighbouring unodes that exceeds a critical angle $\alpha_{\text {hagb }}$. Such new grain boundaries are initially not defined by bnodes, and are thus numerically excluded from grain-boundary migration (Section 2.4.1). Polygonisation requires the creation of new high angle grain boundaries by splitting an existing flynn and inserting new boundary nodes. When intragranular misorientations that exceed $\alpha_{\text {hagb }}$ are detected, grain splitting is activated. This is achieved by finding clusters of unodes with common lattice orientations, separated by high-angle

15 boundaries. The positions of the new boundary nodes are found using a Voronoi decomposition of the unode clusters, storing the Voronoi points surrounding the cluster as new bnodes. The critical angle $\alpha_{\text {hagb }}$ has been suggested to be 3 to $5^{\circ}$ for ice Ih, based on experiments that combine grain boundary properties and high-angular resolution measurements (Weikusat et al., 2011a, b). Here we use $\alpha_{\text {hagb }}=5^{\circ}$.

\subsection{Process coupling}

20 Multi-process modelling of polyphase deformation and recrystallisation is achieved by operator splitting. In Elle, the specific physical processes that contribute to microstructure evolution are programmed as standalone modules. These are coupled by a control program, successively running them in isolation, each for a short numerical time step (Fig. 2a). The numerical setup takes into account the visco-plastic deformation (Section 2.3) and dynamic recrystallisation (DRX, Section 2.4) which here covers grain boundary migration, recovery and polygonisation.

25 The recrystallisation modules are computationally less expensive but require short numerical time steps. To reduce numerical errors, the time step for recrystallisation processes is set 20 times smaller than for deformation (VPFFT). In accordance with the smaller time step, one simulation step comprises one VPFFT step and five subloops that run the recrystallisation codes four times per subloop. This adds up to 20 times more recrystallisation steps than VPFFT steps, but an equal time step for all physical processes. Systematic studies showed that the order of the processes as illustrated in Fig. 2a

30 has no significant influence of the results using the properties described above. 
The Cryosphere Discuss., doi:10.5194/tc-2016-167, 2016

Manuscript under review for journal The Cryosphere

Published: 11 July 2016

(c) Author(s) 2016. CC-BY 3.0 License.

\subsection{Setup of simulations}

Three starting microstructures were used to investigate the effect of visco-plastic deformation and DRX at different area fractions of air inclusions of $0 \%, 5 \%$ and $20 \%$ air phase, termed F00, F05 and F20, respectively (Fig. 2b). All initial microstructures were created from the same $10 \times 20 \mathrm{~cm}^{2}$ foam texture with 3267 grains. Lattice orientations were mapped onto a regular grid of 256x256 unodes with a random initial lattice orientation assigned to each grain. Air inclusions were introduced by setting air properties to the desired area percentage of grains, followed by running solely surface-energy based (static) polyphase grain boundary migration until air inclusion sizes equilibrated in area and shape, using an area energy factor $c=0.1$.

The three starting microstructures were deformed in pure shear with a constant incremental strain of $1 \%$ vertical shortening 10 over 75 simulation steps. Each simulation step comprised 20 recrystallisation steps per VPFFT step and equalled $10^{8} \mathrm{~s}=3.16$ yrs, resulting in a vertical strain rate of $10^{-10} \mathrm{~s}^{-1}$ and deformation up to 53\% vertical shortening. Dislocation glide was assumed for ice Ih crystallography with slip on basal, pyramidal and prismatic planes, using a ratio of basal to non-basal critical resolved shear stresses of $\tau_{\text {basal }} \tau_{\text {non-basal }}=20$. Air was modelled as an incompressible crystalline material with the same crystallography and slip systems as for ice, but with $\tau_{\text {s-air }}$ set 5000 times smaller than $\tau_{\text {basal }}$ of ice. With this assumption,

15 the stress in points belonging to pores can be considered to nearly vanish compared to stresses reached in the solid grains, which is coherent with results from modelling of void growth using a dilatational visco-plastic FFT-based formulation (Lebensohn et al, 2013). The simplification of assuming incompressibility allowed us to exclude the effect of compaction during microstructure evolution.

Temperature throughout the simulations was assumed constant at $-30{ }^{\circ} \mathrm{C}$. A detailed summary of all input properties can be

20 found in Table 1. Where not indicated differently, we employed input parameters as used by Llorens et al. (2016a, Table 1). For comparison of grain size statistics, we additionally performed three normal grain growth (NGG) simulations using solely surface energy driven grain boundary migration and no deformation. The NGG simulations used the three microstructures for F00, F05 and F20 as presented in Fig. 2b and the numerical time step was kept the same as in the deformation simulations.

\section{$25 \quad$ 2.7 Post processing and microstructure imaging}

\subsubsection{Strain rate and strain localisation quantification}

In order to visualize and explain the simulations, some post-processing steps were necessary. Strain rate tensor fields predicted by FFT were transformed in von Mises equivalent strain rates normalizing the von Mises strain rate for each unode to the bulk value of the whole model. The von Mises strain rate $\dot{\varepsilon}_{v M}$ provides a scalar measure of strain rate intensity and was calculated as a function of the symmetric strain rate tensor: 
The Cryosphere Discuss., doi:10.5194/tc-2016-167, 2016

Manuscript under review for journal The Cryosphere

Published: 11 July 2016

(c) Author(s) 2016. CC-BY 3.0 License.

$\dot{\varepsilon}_{v M}=\sqrt{\frac{2}{3} \dot{\varepsilon}_{i j} \dot{\varepsilon}_{i j}}$

In addition, we quantified strain localisation at each step during the simulation. Analogous to Sornette et al. (1993) and Davy et al. (1995), the degree of localisation $F$ was calculated with:

$F=1-\frac{1}{N_{u}} \frac{\left(\sum \dot{\varepsilon}_{v M}\right)^{2}}{\sum \dot{\varepsilon}_{v M}^{2}}$

where $N_{u}$ is the total number of unodes within ice grains and $\dot{\varepsilon}_{v M}$ the von Mises equivalent strain rate of each unode. The localisation factor $F$ ranges from 0 to 1 , such that 0 represents completely homogeneous deformation and 1-1/ $N_{u}$ maximum localisation, where all strain is accommodated by a single unode. Note that Sornette et al. (1993) and Davy et al. (1995) used

10 a slightly different localisation factor $f=1-F$, where 1 represents homogeneous deformation.

\subsubsection{Driving forces and crystallographic orientations}

For each step of grain boundary migration, the driving forces for migration were stored in bnode attributes differentiating between surface and stored strain energy driving forces. Details about the driving force calculation can be found in Llorens et al. (2016a, equations 10-12). By normalizing the local stored strain energy to bnode mean surface energy, we obtained a

15 quantitative measure of how much grain boundary migration is induced by strain energy. For each simulation step, the bnodes only stored the driving forces for the last grain boundary migration step. This allowed to capture the correct driving forces at the end of the simulation step after a time increment during which strain energy was induced by deformation and reduced by recrystallisation processes. Hence, we determined a minimum estimate for strain energies, which may have been higher in an intermediate stage of the simulation step.

20 Crystallographic preferred orientations were stored and updated during the simulations. Pole figures and Eigenvalues were extracted using the texture analysis software MTEX (Bachmann et al., 2010; Mainprice et al., 2011) based on the orientation distribution function. The projection plane was chosen to be parallel to the $x-y$ plane of the numerical model and c-axis orientation was expressed using the angles of azimuth and dip in this plane.

\subsubsection{Microstructure mapping of natural samples}

25 To qualitatively compare the simulation results to natural firn microstructures, we utilized an image from a firn sample taken from the EPIA Dronning Maud Land ice core (EDML) site, Antarctica. The sample was cut from a core from $80 \mathrm{~m}$ depth. Using density and annual-layer thickness data of Kipfstuhl et al. (2009) for the EDML core, the density is about $800 \mathrm{~kg} / \mathrm{m}^{3}$ at $80 \mathrm{~m}$ depth and the total vertical shortening up to $50 \%$ (Faria et al., 2014b estimated this value based on the supplementary material from Ruth et al., 2007). A plane was cut from the sample and prepared for microstructure mapping (Kipfstuhl et al., 
The Cryosphere Discuss., doi:10.5194/tc-2016-167, 2016

Manuscript under review for journal The Cryosphere

Published: 11 July 2016

(c) Author(s) 2016. CC-BY 3.0 License.

2009). The microstructure mapping technique allows detailed imaging of ice, air bubbles, (sub-) grain boundaries and other microstructural features typically found in polar ice. It is based on keeping a polished sample surface in a cold, yet dry environment, causing preferred ice sublimation at (sub-) grain boundaries. After sublimation, the prepared sample surface is scanned using a Large area scan macroscope (Krischke et al., 2015) highlighting topographical changes on the surface in a grey-scale image.

\section{Results}

Table 2 and Fig. 3 provide an overview of the results obtained from simulating pure shear deformation with ongoing recrystallisation for three different amounts of air inclusions. Selected movies illustrating the full microstructure evolution can be found as supplementary material in the AV Portal of TIB Hannover (av.tib.eu). The resulting microstructures are characterized by heterogeneous grain size distributions and a slight increase in average grain sizes compared to the initial one. Most grains have smoothly curved boundaries and are usually equidimensional to slightly elongate in the $x$-direction. Coalescence of air inclusions (Roessiger et al., 2014) led to a number of large inclusions in simulation F20. The largest air inclusions show a marked elongation, mostly oblique to the shortening direction. Small inclusions remained circular.

The strain and strain rate distribution is difficult to discern from the final air inclusion and grain shapes only, as these are constantly reworked by DRX (Llorens et al., 2016b). Instantaneous strain rate maps and finite strain passive marker grids provide better insight in deformation heterogeneity (Fig. 3), which is also visible in movies that show the whole deformation history (AV Portal of TIB Hannover, av.tib.eu). Strain localisation is observed in all simulations independent of the presence of air inclusions. While instantaneous strain rate maps (Fig. 3b) can only show localisation at the current time step, passive marker grids reflect the accumulated strain throughout the microstructure evolution (Fig. 3a-b). Figure $3 b$ shows that zones with high strain rates, are oriented at $\leq 45^{\circ}$ to the shortening direction. Zones with a high finite strain, or shear bands, are visible in the finite-strain pattern. These zones of accumulated shear strain initially formed at ca. $45^{\circ}$ and subsequently rotated away from the shortening direction, especially in air-free ice (F00). High strain (-rate) zones form bridges between air inclusions when these are present. Regions between the high strain zones are characterized by both low strain rates and low accumulated finite strains.

25 Using the localisation factor $F$, it is possible to quantify the degree of strain localisation in our simulations. Figure 4 shows the evolution of this factor with strain for all simulations. In accordance with strain rate maps and passive marker grids, nonzero $(F \geq 0.3)$ values are observed throughout the simulations, indicating strain localisation in all cases. $F$ increases up to about $40 \%$ vertical shortening, after which the rate of increase is lower. Localisation increases with the amount of air inclusions, with $F \approx 0.5-07$ in simulation $\mathrm{F} 20$ about double that for pure ice ( $\mathrm{F} \approx 0.3-0.35$ ).

30 To investigate the competition between surface and stored strain energies in grain boundary migration, the strain energy driving forces for simulation F20 were normalized to mean surface energies and plotted for each bnode (Fig. 5a). The colour scale is adjusted to plot bnodes without a contribution of strain-induced energies in the background colour (blue). Boundaries 
The Cryosphere Discuss., doi:10.5194/tc-2016-167, 2016

Manuscript under review for journal The Cryosphere

Published: 11 July 2016

(c) Author(s) 2016. CC-BY 3.0 License.

with a significant contribution of stored strain energies are indicated by green to red colours. A comparison with Fig. 3 shows that grain boundary migration that is driven mostly by strain energy (bright colours) are predominantly located in high strain (-rate) zones. Examples are indicated by large arrows in Fig. 5a and between three elongated and large air inclusions in the lower middle region of the final microstructure of F20. Conversely, the contributions of surface and strain energy to

5 grain-boundary migration are about equal in less-strained areas.

Qualitatively, microstructure images show a heterogeneous grain size distribution (Fig. 3). To further visualize the spatial distribution of grain sizes, the microstructure in Fig. 5b shows ice grains coloured according to their area. Analogous to the driving force distribution for grain-boundary migration, we observe the smallest grains between air inclusions coinciding with zones of marked strain localisation.

10 Figure 6 depicts ice grain size statistics for the final microstructures. To visualise the influence of dynamic recrystallisation, grain size histograms are compared with normal grain growth (NGG) simulation results. All simulations show an increase of average grain areas with respect to the initial mean grain sizes (Fig. 6, Table 1). However, dynamic recrystallisation simulations resulted in a grain size distribution skewed towards smaller grain sizes than for NGG simulations. Furthermore, the distribution of grain sizes is broadened when dynamic recrystallisation was active. With increasing amount of air in

15 simulations F05 and F20, the average grain-size increase compared to the initial state is lower for both dynamic recrystallisation and NGG results.

Crystallographic preferred orientations in simulations are visualised using pole figures and maps of c-axis azimuths (Fig. 7). The evolution of orientations is also illustrated in movies to be found in the AV Portal of TIB Hannover (av.tib.eu). After $53 \%$ of vertical shortening, the initially random fabric is re-arranged with c-axes preferentially oriented parallel to the

20 vertical shortening direction (Fig. 7a). This maximum becomes less pronounced with increasing amount of air as reflected in pole figures and quantified by a decrease in first eigenvalues of the orientation distribution from 0.80 (F00) to 0.69 (F20). This trend is also visible in c-axis orientation maps (Fig. 7b), which shows a more heterogeneous distribution of well-aligned and random fabrics with increasing air content. Most grains in simulation F00 have c-axes azimuths parallel to the y-axis. Grains within high strain bands by a slight tilt of the c-axes to the left or right, depending on the orientation of the shear

25 bands. In contrast, simulation F05 and, even more, F20 show areas of small grains with c-axes strongly aligned perpendicular to high strain bands (white arrows in Fig. 7b). This means that the basal planes are aligned parallel to these bands. In low strain areas, such as the middle part of the F20 model, a much more random c-axis distribution is observed (white circle in Fig. 7b) compared to simulation F00.

For comparison with natural ice and firn core examples, a microstructure image from $80 \mathrm{~m}$ depth from the EDML site was

30 provided. Apart from the scale difference, the F20 and EDML microstructure show some distinct similarities (Fig. 8), in particular in the heterogeneity in grain shape and size distribution. Detail area A in Fig. 8 contains larger grains, with more $120^{\circ}$ angles at triple junctions and a lower density of subgrain boundaries than area B between bubbles. Similar areas can be found in simulation F20. While area $\mathrm{C}$ has large grains with straight grain boundaries and $120^{\circ}$ angles at triple junctions (comparable to A), area D is characterised by small grains between the bubbles that are occasionally elongated and show 
The Cryosphere Discuss., doi:10.5194/tc-2016-167, 2016

Manuscript under review for journal The Cryosphere

Published: 11 July 2016

(c) Author(s) 2016. CC-BY 3.0 License.

other triple junction angles (comparable to B). As an estimate for subgrain boundary density, average misorientation between unodes was plotted underneath the grain boundary network. In detail image D, we observe a higher density of subgrain boundaries as illustrated by higher average misorientations than in area $\mathrm{C}$.

\section{Discussion}

\section{4.1 Strain localisation}

Our simulations indicate a distinct strain localisation in both pure ice and ice with bubbles. Strain localisation is not a transient effect, but actually increases, at least up to about $40 \%$ of strain (Fig. 4). Strain localisation in pure ice (F00) is related to the plastic anisotropy of the ice crystal. Grains, or clusters of grains, with initially suitable orientations for slip accommodate strain more efficiently and thus initiate the first regions of strain-rate localisation. With progressive strain

10 these localisation zones may strengthen as the basal planes align themselves with the local shear plane, or they are deactivated when either the internal lattice orientations or the orientation of the localisation zones become less suitable for further localisation. Once deactivated, the localised zones only rotate and move passively with the bulk deformation, and may remain visible as shear bands in the finite strain grid.

In the presence of air inclusions, localisation zones are forming at bridges between the inclusions where stresses are highest.

15 Even in the absence of plastic anisotropy this leads to the formation of localisation zones, especially in power-law materials (Jessell et al., 2009). With increasing air fraction, the arrangement and geometry of air inclusions become the main controllers of strain localisation in the ice-air aggregates and crystallographic orientations exert only a secondary control. The additional localisation mechanism causes stronger localisation in ice with air than without air.

The localisation zones enclose lozenge-shaped areas of low strain rate, which we term microlithons, in keeping with

20 terminology used in geology (e.g. Passchier and Trouw, 2005 p. 78). In pure ice, the CPO within the microlithons is strong and trends towards a single maximum fabric. With air inclusions causing intensified strain localisation, the CPO is expected to be more heterogeneous with differences between high- and low-strain rate zones. Within localisation zones, the basal planes rotate towards the local shear plane, causing a divergence of the c-axes azimuths away from the vertical compression direction. This is in contrast to the microlithons, in which CPO development is slower because of the relatively low strain rate. The weaker bulk single-maximum fabric with increasing amount of air is thus an effect of air inclusions causing distinctly localised zones that accommodate most of the deformation, and less deformed microlithons that preserve the initial fabric. Our results are an illustrative example of the role of second phases on CPO development. If the weak phase is the secondary phase and the strong phase is load bearing, as in our simulations, strain localisation controlled by the distribution of second-phase inclusions. This produces a locally weaker CPO in the microlithons, but also in the bulk material.

30 Grain boundary sliding is assumed to be an explanation for a weaker CPO in polyphase materials (e.g. Fliervoet et al., 1997). However, a weaker CPO with increasing content of the second phase is found in our simulations, in the complete absence of grain-boundary sliding. Therefore, a weaker CPO alone should not be regarded as unambiguous evidence for grain-boundary 
The Cryosphere Discuss., doi:10.5194/tc-2016-167, 2016

Manuscript under review for journal The Cryosphere

Published: 11 July 2016

(c) Author(s) 2016. CC-BY 3.0 License.

sliding. This supports studies indicating a very shallow onset of plastic deformation in the ice sheets (Freitag et al., 2008) and absence of grain boundary sliding (Theile et al., 2011).

\subsection{Implications of strain localisation for the occurrence of dynamic recrystallisation}

According to published deformation mechanism maps (Shoji and Higashi, 1978; Goldsby, 2006), dislocation creep is to be

5 expected for the average grain size, strain rate and temperature of our simulations. Also, the effective density of the simulation F20 (approximately $750 \mathrm{~kg} \mathrm{~m}^{-3}$ ) is above the critical density of $550 \mathrm{~kg} \mathrm{~m}^{-3}$ where plastic deformation via dislocation creep is classically supposed to dominate (Maeno and Ebinuma, 1983). Therefore, we assume that our model assumption of deformation accommodated by dislocation creep only is sufficient to draw conclusions on mechanisms acting at comparable densities and depth in nature.

10 With the assumption of dislocation glide as the only strain accommodating mechanism, the dislocation density is expected to increase unless recovery reduces densities by re-arrangement of misorientations in lower energy configurations. A localisation in strain results in higher strain gradients at the localisation zone margins and hence locally higher strain energies. It is therefore associated with locally enhanced strain-induced boundary migration, as can be seen in Fig. 5a. This is in accordance with Weikusat et al. (2009) stating that strain-induced boundary migration occurs localized and the driving

15 forces have to be considered locally. Duval (1985) argued that the strain energy in firn should be small in comparison with surface energies and Duval and Castelnau (1995) conclude that a temperature of $-10{ }^{\circ} \mathrm{C}$ or higher is essential for straininduced boundary migration. This led to the assumption by De la Chapelle et al. (1998) that dynamic recrystallisation is essentially restricted to the basal part of ice sheets and therefore an improbable process in firn.

Faria et al. (2014b, p. 45) theoretically discuss the relation of strain localisation to localized dynamic recrystallisation in firn.

20 They state that although the overall stresses and strains in firn are low, it is "characterised by large strain variability" and locally highly increased stresses and strains depending on the geometry of the air bubble network. They further conclude that stored strain energy could be very high in particular regions of the ice skeleton causing dynamic recrystallisation to start in shallow levels. Our simulations are coherent with this statement and confirm the theoretical predictions by Faria et al. (2014b).

25 Since improving microstructural imaging methods by Kipfstuhl et al. (2006) gave further insight in firn microstructures, studies by Weikusat et al. (2009) and Kipfstuhl et al. (2009) gave microstructural evidence for dynamic recrystallisation in shallow parts of the ice column and firn. In contrast to assumptions by for instance De la Chapelle et al. (1998), it therefore seems probable that dynamic recrystallisation already takes place at very shallow levels in the ice sheet, at least in localised zones. Our simulations at $-30^{\circ} \mathrm{C}$ as well as observations of natural firn microstructures at EDML ice coring site (Kipfstuhl et

30 al. 2009, Fig. 8) with approximately $-45^{\circ} \mathrm{C}$ annual mean temperature (Oerter et al. 2009), indicate that the initiation of this process is not only temperature dependent. It is also a function of strain rate, since locally high strain rates and stress concentrations at bridges between the air inclusions induce high driving forces. This is in accordance with the 
The Cryosphere Discuss., doi:10.5194/tc-2016-167, 2016

Manuscript under review for journal The Cryosphere

Published: 11 July 2016

(c) Author(s) 2016. CC-BY 3.0 License.

recrystallisation diagram by Faria et al. (2014b), in which the occurrence of recrystallisation mechanisms is essentially a function of temperature and strain rate (i.e. work rate, which is the product of stress and strain rate), rather than depth.

Our numerically modelled microstructures resemble patterns observed in natural firn microstructures from EDML site (Fig. 8), supporting the microstructural evidence for the occurrence of dynamic recrystallisation in firn from the EDML ice core

5 site (Kipfstuhl et al., 2009). However, the scale differs with the mean grain size in the models about one order of magnitude larger than in the EDML sample. It should be noted that the experimental strain rate $\left(10^{-10} \mathrm{~s}^{-1}\right)$ is also about ten times larger than the $7.4 \cdot 10^{-12} \mathrm{~s}^{-1}$ strain rate estimated for the sample (Faria et al., 2014b).

It should be noted that the strain rate in our simulations $\left(10^{-10} \mathrm{~s}^{-1}\right)$ is an order of magnitude faster than assumed for the $80 \mathrm{~m}$ deep sample from the EDML core (Faria et al., 2014b). Modelling a slower strain rate is possible, but currently too time 10 consuming. From a technical point of view, fast strain rates lead to numerical error reduction as the time steps for recrystallisation codes can be low. To achieve slower strain rates at the same time step, the number of recrystallisation steps per deformation step needs to be increased at a significant expense of computation time.

According to the dynamic recrystallisation diagram by Faria et al. (2014b), a lower strain rate would decrease the contribution of rotation recrystallisation and increase that of strain-induced grain boundary migration to the final

15 microstructure. This would reduce the difference in grain size between high- and low-strain zones. A difference variation in grain size is, however, still observable in the EDML sample, indicating that grain-boundary migration was not able to obliterate the effects of rotation recrystallisation in these suspected high-strain zones, even at the lower natural strain rate.

Because of dynamic recrystallisation, grain shapes are mostly equidimensional, even in the highest-strain bands. Recrystallisation thus masks the localisation in the microstructure (Llorens et al., 2016b), making it difficult to discern in 20 natural samples. Subtle indications of localisation may, however, be zones with a deviating lattice orientation (Fig. 7) (Jansen et al., 2016) or zones with a smaller grain size (Fig. 5b). In single phase ice, where localisation zones shift through the material, only the youngest localisation zones may be visible, as the microstructure is reset in extinct localisation bands (compare simulation F00 in Fig. 3 and 7) (Jansen et al., 2016). Since bubbles fix the locations of shear localisation, their presence may be more obvious in natural samples, such as the one from the EDML (Fig. 8). Only if bubbles are large and strain rates high enough the elongate shape of the largest bubbles can be used to discern localisation zones (simulation F20).

\subsection{Grain size analyses}

Grain size statistics of the simulation results provide a comparison between the distribution for the non-deformation related normal grain growth (NGG) and deformation induced dynamic recrystallisation with varying amounts of air. An increase in grain size is observed in all cases, but less for dynamic recrystallisation and also less with an increasing amount of air

30 inclusions. The observation of a lower final grain sizes for higher amounts of air is related to the growth regimes presented by Roessiger et al. (2014) based on numerical simulations on NGG in ice-air aggregates: (1) The first regime is characterised by ice grain sizes lower than bubble spacing, where most grains can grow unhindered by bubbles as in single phase polycrystalline ice. The growth rate is constant. (2) The second regime is a transitional regime, where bubble spacing is close 
The Cryosphere Discuss., doi:10.5194/tc-2016-167, 2016

Manuscript under review for journal The Cryosphere

Published: 11 July 2016

(c) Author(s) 2016. CC-BY 3.0 License.

to the grain diameter and the growth rate decreases. (3) In the third regime, all grains are in contact with bubbles. A slow, but steady growth rate is reached again, controlled by the coalescence rate of bubbles that increases their spacing. In our case, NGG in the simulations with air inclusions is slowed down, indicating regime (2) growth with a small, but significant fraction of the grains in contact with inclusions, and thus hindered in their growth (Fig. 6).

5 In comparison with NGG simulations, our VPFFT simulations with dynamic recrystallisation show smaller final grain sizes and broader distributions. The broadening reflects the microstructural heterogeneity induced by dynamic recrystallisation (in particular grain splitting during rotation recrystallisation) and strain localisation. Locally, grains size has remained small due to rotation recrystallisation, whereas in other, low strain-rate regions, grain sizes have increased. Here surface energy constituted a significant, if not dominant, proportion of the driving force for grain boundary migration. These results are

10 consistent with the observed broadening of the grain size distribution with depth in firn from the EDML site (Kipfstuhl et al., 2009), accompanied by an increasing number of deformation-related substructures such as subgrain boundaries and irregular boundary shapes. Our modelling confirms the interpretation by Kipfstuhl et al. (2009) that this trend is related to the onset of dynamic recrystallisation. We refrain from a detailed comparison of our grain-size data and those observed in nature as a discussion of the stereologic issues related to our 2D model and sections through 3D natural samples would be beyond the scope of this paper.

\section{Conclusions}

We used polyphase numerical models of deformation and recrystallisation to investigate the occurrence of dynamic recrystallisation in an air-ice composite such as polar ice and firn. To our knowledge this provides the first full-field numerical simulation results on dynamic recrystallisation in polyphase crystalline aggregates in glaciology. Our simulated

20 microstructures resemble those from the EDML ice core site. We show that strain and strain-rate localisation is to be expected during ice deformation, forming shear bands that accommodate significant amounts of strain. Localisation is caused by the mechanical anisotropy of ice Ih that deforms by dislocation glide, and is intensified between air inclusions. We conclude that dynamic recrystallisation is occurring in very shallow levels of the ice sheet where it is related to strain localisation and stress concentrations between the air inclusions.

\section{Acknowledgements}

We are thankful for support and helpful discussions with the members of the Elle community. We thank Sepp Kipfstuhl and Johannes Freitag for their input to improve the manuscript. This study was funded by the DFG (SPP 1158) grant BO 1776/12-1. Furthermore, we acknowledge funding by the Helmholtz Junior Research group "The effect of deformation mechanisms for ice sheet dynamics" (VH-NG-802) and traveling funds for presenting and improving this study by the 
The Cryosphere Discuss., doi:10.5194/tc-2016-167, 2016

Manuscript under review for journal The Cryosphere

Published: 11 July 2016

(c) Author(s) 2016. CC-BY 3.0 License.

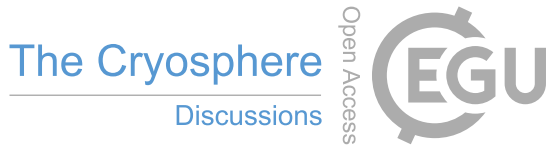

(c) (i)

EPICA Descartes travel price, the ESF research networking programme on the microdynamics of ice (MicroDICE) and the Helmholtz Graduate School for Polar and Marine Research (POLMAR).

\section{References}

Alley, R. B.: Texture of polar firn for remote sensing, Annals of Glaciology, 9, 1-4, 1987.

5 Alley, R. B., Gow, A. J., and Meese, D. A.: Mapping c-axis fabrics to study physical processes in ice, Journal of Glaciology, 41, 197-203, 1995.

Anderson, D. L., and Benson, C. S.: The densification and diagenesis of snow, in: Ice and Snow: Properties, Processes and Applications, MIT Press, 1963.

Arena, L., Nasello, O. B., and Levi, L.: Effect of bubbles on grain growth in ice, The Journal of Physical Chemistry B, 101,

10 6109-6112, 1997.

Azuma, N., and Higashi, A.: Formation processes of ice fabric pattern in ice sheets, Annals of Glaciology, 6, 130-134, 1985.

Azuma, N., Miyakoshi, T., Yokoyama, S., and Takata, M.: Impeding effect of air bubbles on normal grain growth of ice, Journal of Structural Geology, 42, 184-193, 2012.

Bachmann, F., Hielscher, R., and Schaeben, H.: Texture analysis with MTEX-free and open source software toolbox, Solid

15 State Phenomena, 160, 63-68, 2010.

Becker, J. K., Bons, P. D., and Jessell, M. W.: A new front-tracking method to model anisotropic grain and phase boundary motion in rocks, Computers \& Geosciences, 34, 201-212, 2008.

Blackford, J. R.: Sintering and microstructure of ice: a review, Journal of Physics D: Applied Physics, 40, R355, 2007.

Bons, P., Koehn, D., and Jessell, M.: Microdynamics Simulation, Volume 106 of Lecture Notes in Earth Sciences, Springer

20 Berlin Heidelberg, 2008.

Bons, P. D., Jansen, D., Mundel, F., Bauer, C. C., Binder, T., Eisen, O., Jessell, M. W., Llorens, M.-G., Steinbach, F., Steinhage, D., and Weikusat, I.: Converging flow and anisotropy cause large-scale folding in Greenland's ice sheet, Nature Communications, 7, 2016.

Borthwick, V. E., Piazolo, S., Evans, L., Griera, A., and Bons, P. D.: What happens to deformed rocks after deformation? A

25 refined model for recovery based on numerical simulations, Geological Society, London, Special Publications, 394, 215-234, 2014.

Brinckmann, S., Siegmund, T., and Huang, Y.: A dislocation density based strain gradient model, International Journal of Plasticity, 22, 1784-1797, 2006.

Budd, W., and Jacka, T.: A review of ice rheology for ice sheet modelling, Cold Regions Science and Technology, 16, 107$30 \quad 144,1989$.

Colbeck, S.: Theory of metamorphism of dry snow, Journal of Geophysical Research: Oceans, 88, 5475-5482, 1983. 
The Cryosphere Discuss., doi:10.5194/tc-2016-167, 2016

Manuscript under review for journal The Cryosphere

Published: 11 July 2016

(c) Author(s) 2016. CC-BY 3.0 License.

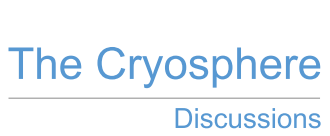

(c) (i)

Davy, P., Hansen, A., Bonnet, E., and Zhang, S.-Z.: Localization and fault growth in layered brittle-ductile systems: Implications for deformations of the continental lithosphere, Journal of Geophysical Research: Solid Earth, 100, 6281-6294, 1995

De La Chapelle, S., Castelnau, O., Lipenkov, V., and Duval, P.: Dynamic recrystallization and texture development in ice as 5 revealed by the study of deep ice cores in Antarctica and Greenland, Journal of Geophysical Research: Solid Earth, 103, 5091-5105, 1998.

Duval, P.: Creep and recrystallization of polycrystalline ice, Bulletin de Mineralogie, 102, 80-85, 1979.

Duval, P.: Grain growth and mechanical behaviour of polar ice, Annals of Glaciology, 6, 79-82, 1985.

Duval, P., and Castelnau, O.: Dynamic Recrystallization of Ice in Polar Ice Sheets, Journal de Physique IV, 05, C3-197-

10 C193-205-C193, 1995.

Duval, P., Ashby, M. F., and Anderman, I.: Rate-controlling processes in the creep of polycrystalline ice, The Journal of Physical Chemistry, 87, 4066-4074, 1983.

Duval, P., Arnaud, L., Brissaud, O., Montagnat, M., and de La Chapelle, S.: Deformation and recrystallization processes of ice from polar ice sheets, Annals of Glaciology, 30, 83-87, 2000.

15 Faria, S. H., Freitag, J., and Kipfstuhl, S.: Polar ice structure and the integrity of ice-core paleoclimate records, Quaternary Science Reviews, 29, 338-351, 2010.

Faria, S. H., Weikusat, I., and Azuma, N.: The microstructure of polar ice. Part I: Highlights from ice core research, Journal of Structural Geology, 61, 2-20, 2014a.

Faria, S. H., Weikusat, I., and Azuma, N.: The microstructure of polar ice. Part II: State of the art, Journal of Structural 20 Geology, 61, 21-49, 2014b.

Fischer, H., Behrens, M., Bock, M., Richter, U., Schmitt, J., Loulergue, L., Chappellaz, J., Spahni, R., Blunier, T., Leuenberger, M., and Stocker, T. F.: Changing boreal methane sources and constant biomass burning during the last termination, Nature, 452, 864-867, 2008.

Fliervoet, T. F., White, S. H., and Drury, M. R.: Evidence for dominant grain-boundary sliding deformation in greenschistand amphibolite-grade polymineralic ultramylonites from the Redbank Deformed Zone, Central Australia, Journal of Structural Geology, 19, 1495-1520, 1997.

Freitag, J., Kipfstuhl, S., and Faria, S. H.: The connectivity of crystallite agglomerates in low-density firn at Kohnen station, Dronning Maud Land, Antarctica, Annals of Glaciology, 49, 114-120, 2008.

Glen, J.: The flow law of ice: A discussion of the assumptions made in glacier theory, their experimental foundations and 30 consequences, IASH Publ, 47, 171-183, 1958.

Goldsby, D. L.: Superplastic Flow of Ice Relevant to Glacier and Ice-Sheet Mechanics, Glacier Science and Environmental Change, 308-314, 2006.

Gow, A. J.: On the rates of growth of grains and crystals in south polar firn, Journal of Glaciology, 8, 241-252, 1969. 
The Cryosphere Discuss., doi:10.5194/tc-2016-167, 2016

Manuscript under review for journal The Cryosphere

Published: 11 July 2016

(c) Author(s) 2016. CC-BY 3.0 License.

Griera, A., Bons, P. D., Jessell, M. W., Lebensohn, R. A., Evans, L., and Gomez-Rivas, E.: Strain localization and porphyroclast rotation, Geology, 39, 275-278, 2011.

Griera, A., Llorens, M.-G., Gomez-Rivas, E., Bons, P. D., Jessell, M. W., Evans, L. A., and Lebensohn, R.: Numerical modelling of porphyroclast and porphyroblast rotation in anisotropic rocks, Tectonophysics, 587, 4-29, 2013.

5 Herron, M. M., and Langway Jr, C. C.: Firn densification: an empirical model, Journal of Glaciology, 25, 373-385, 1980.

Hirth, G., and Tullis, J.: Dislocation creep regimes in quartz aggregates, Journal of Structural Geology, 14, 145-159, 1992.

Humphreys, F. J., and Hatherly, M.: Recrystallization and related annealing phenomena, Elsevier, 2004.

Jacka, T. H., and Li, J.: The steady-state crystal size of deforming ice, Annals of Glaciology, 20, 13-18, 1994.

Jansen, D., Llorens, M. G., Westhoff, J., Steinbach, F., Kipfstuhl, S., Bons, P. D., Griera, A., and Weikusat, I.: Small-scale

10 disturbances in the stratigraphy of the NEEM ice core: observations and numerical model simulations, The Cryosphere, 10, 359-370, 2016.

Jessell, M., Bons, P., Evans, L., Barr, T., and Stüwe, K.: Elle: the numerical simulation of metamorphic and deformation microstructures, Computers \& Geosciences, 27, 17-30, 2001.

Jessell, M. W., Bons, P. D., Griera, A., Evans, L. A., and Wilson, C. J. L.: A tale of two viscosities, Journal of Structural

15 Geology, 31, 719-736, 2009.

Ketcham, W. M., and Hobbs, P. V.: An experimental determination of the surface energies of ice, Philosophical Magazine, 19, 1161-1173, 1969.

Kipfstuhl, S., Hamann, I., Lambrecht, A., Freitag, J., Faria, S. H., Grigoriev, D., and Azuma, N.: Microstructure mapping: a new method for imaging deformation-induced microstructural features of ice on the grain scale, Journal of glaciology, 52,

$20 \quad 398-406,2006$.

Kipfstuhl, S., Faria, S. H., Azuma, N., Freitag, J., Hamann, I., Kaufmann, P., Miller, H., Weiler, K., and Wilhelms, F.: Evidence of dynamic recrystallization in polar firn, Journal of Geophysical Research: Solid Earth (1978-2012), 114, 2009.

Krischke, A., Oechsner, U., and Kipfstuhl, S.: Rapid Microstructure Analysis of Polar Ice Cores, Optik \& Photonik, 10, 32$35,2015$.

25 Lebensohn, R. A.: N-site modeling of a 3D viscoplastic polycrystal using Fast Fourier Transform, Acta Materialia, 49, 27232737, 2001.

Lebensohn, R. A., Montagnat, M., Mansuy, P., Duval, P., Meysonnier, J., and Philip, A.: Modeling viscoplastic behavior and heterogeneous intracrystalline deformation of columnar ice polycrystals, Acta Materialia, 57, 1405-1415, 2009.

Lebensohn, R. A., Escobedo, J. P., Cerreta, E. K., Dennis-Koller, D., Bronkhorst, C. A., and Bingert, J. F.: Modeling void 30 growth in polycrystalline materials, Acta Materialia, 61, 6918-6932, 2013.

Llorens, M.-G., Bons, P. D., Griera, A., and Gomez-Rivas, E.: When do folds unfold during progressive shear? Geology, 41, 563-566, 2013a.

Llorens, M.-G., Bons, P. D., Griera, A., Gomez-Rivas, E., and Evans, L. A.: Single layer folding in simple shear, Journal of Structural Geology, 50, 209-220, 2013 b. 
The Cryosphere Discuss., doi:10.5194/tc-2016-167, 2016

Manuscript under review for journal The Cryosphere

Published: 11 July 2016

(c) Author(s) 2016. CC-BY 3.0 License.

Llorens, M.-G., Griera, A., Bons, P. D., Roessiger, J., Lebensohn, R., Evans, L., and Weikusat, I.: Dynamic recrystallisation of ice aggregates during co-axial viscoplastic deformation: a numerical approach, Journal of Glaciology, FirstView, 1-19, $2016 \mathrm{a}$.

Llorens, M.-G., Griera, A., Bons, P. D., Lebensohn, R., Evans, L., Jansen, D. and Weikusat, I.: Full-field prediction of ice 5 dynamic recrystallisation under simple shear conditions, Earth and Planetary Science Letters, 2016b, in press, DOI: 10.1016/j.epsl.2016.06.045

Luethi, D., Le Floch, M., Bereiter, B., Blunier, T., Barnola, J.-M., Siegenthaler, U., Raynaud, D., Jouzel, J., Fischer, H., Kawamura, K., and Stocker, T. F.: High-resolution carbon dioxide concentration record 650,000-800,000 years before present, Nature, 453, 379-382, 2008.

10 Maeno, N., and Ebinuma, T.: Pressure sintering of ice and its implication to the densification of snow at polar glaciers and ice sheets, The Journal of Physical Chemistry, 87, 4103-4110, 1983.

Mainprice, D., Hielscher, R., and Schaeben, H.: Calculating anisotropic physical properties from texture data using the MTEX open-source package, Geological Society, London, Special Publications, 360, 175-192, 2011.

Montagnat, M., Blackford, J. R., Piazolo, S., Arnaud, L., and Lebensohn, R. A.: Measurements and full-field predictions of 15 deformation heterogeneities in ice, Earth and Planetary Science Letters, 305, 153-160, 2011.

Montagnat, M., Castelnau, O., Bons, P. D., Faria, S. H., Gagliardini, O., Gillet-Chaulet, F., Grennerat, F., Griera, A., Lebensohn, R. A., Moulinec, H., Roessiger, J., and Suquet, P.: Multiscale modeling of ice deformation behavior, Journal of Structural Geology, 61, 78-108, 2014.

Nasello, O. B., Prinzio, C. L. D., and Guzmán, P. G.: Temperature dependence of "pure" ice grain boundary mobility, Acta 20 Materialia, 53, 4863-4869, 2005.

Oerter, H., Druecker, C., Kipfstuhl, S., and Wilhelms, F.: Kohnen station-the drilling camp for the EPICA deep ice core in Dronning Maud Land, 2009.

Passchier, C. W., and Trouw, R. A. J.: Microtectonics, Springer, 2005.

Petrenko, V. F., and Whitworth, R. W.: Physics of ice, Clarendon Press, 1999.

25 Piazolo, S., Jessell, M. W., Bons, P. D., Evans, L., and Becker, J. K.: Numerical simulations of microstructures using the Elle platform: a modern research and teaching tool, Journal of the Geological Society of India, 75, 110-127, 2010.

Riche, F., Montagnat, M., and Schneebeli, M.: Evolution of crystal orientation in snow during temperature gradient metamorphism, Journal of Glaciology, 59, 47-55, 2013.

Rignot, E., Mouginot, J., and Scheuchl, B.: Ice flow of the Antarctic ice sheet, Science, 333, 1427-1430, 2011.

30 Roessiger, J., Bons, P. D., Griera, A., Jessell, M. W., Evans, L., Montagnat, M., Kipfstuhl, S., Faria, S. H., and Weikusat, I.: Competition between grain growth and grain-size reduction in polar ice, Journal of Glaciology, 57, 942-948, 2011.

Roessiger, J., Bons, P. D., and Faria, S. H.: Influence of bubbles on grain growth in ice, Journal of Structural Geology, 61, 123-132, 2014. 
The Cryosphere Discuss., doi:10.5194/tc-2016-167, 2016

Manuscript under review for journal The Cryosphere

Published: 11 July 2016

(c) Author(s) 2016. CC-BY 3.0 License.

Ruth, U., Barnola, J. M., Beer, J., Bigler, M., Blunier, T., Castellano, E., Fischer, H., Fundel, F., Huybrechts, P., Kaufmann, P., Kipfstuhl, S., Lambrecht, A., Morganti, A., Oerter, H., Parrenin, F., Rybak, O., Severi, M., Udisti, R., Wilhelms, F., and Wolff, E.: "EDML1": a chronology for the EPICA deep ice core from Dronning Maud Land, Antarctica, over the last 150 000 years, Clim. Past, 3, 475-484, 2007

5 Schulson, E. M., and Duval, P.: Creep and fracture of ice, Cambridge University Press Cambridge, 2009.

Schwander, J., and Stauffer, B.: Age difference between polar ice and the air trapped in its bubbles, Nature, 311, 45-47, 1984.

Shoji, H., and Higashi, A.: A deformation mechanism map of ice, Journal of Glaciology, 21, 419-427, 1978.

Sornette, A., Davy, P., and Sornette, D.: Fault growth in brittle-ductile experiments and the mechanics of continental

10 collisions, Journal of Geophysical Research: Solid Earth, 98, 12111-12139, 1993.

Stauffer, B., Schwander, J., and Oeschger, H.: Enclosure of air during metamorphosis of dry firn to ice, Annals of Glaciology, 6, 108-112, 1985.

Stephenson, P. J.: Some considerations of snow metamorphism in the Antarctic ice sheet in the light of ice crystal studies, Physics of Snow and Ice, 1, 725-740, 1967.

15 Theile, T., Löwe, H., Theile, T. C., and Schneebeli, M.: Simulating creep of snow based on microstructure and the anisotropic deformation of ice, Acta Materialia, 59, 7104-7113, 2011.

Treverrow, A., Budd, W. F., Jacka, T. H., and Warner, R. C.: The tertiary creep of polycrystalline ice: experimental evidence for stress-dependent levels of strain-rate enhancement, Journal of Glaciology, 58, 301-314, 2012.

Urai, J. L., Means, W. D., and Lister, G. S.: Dynamic recrystallization of minerals, in: Mineral and rock deformation:

20 laboratory studies, American Geophysical Union Washington, DC, 161-199, 1986.

Weikusat, I., Kipfstuhl, S., Faria, S. H., Azuma, N., and Miyamoto, A.: Subgrain boundaries and related microstructural features in EDML (Antarctica) deep ice core, Journal of Glaciology, 55, 461-472, 2009.

Weikusat, I., de Winter, D., Pennock, G., Hayles, M., Schneijdenberg, C., and Drury, M.: Cryogenic EBSD on ice: preserving a stable surface in a low pressure SEM, Journal of microscopy, 242, 295-310, $2011 \mathrm{a}$.

25 Weikusat, I., Miyamoto, A., Faria, S. H., Kipfstuhl, S., Azuma, N., and Hondoh, T.: Subgrain boundaries in Antarctic ice quantified by X-ray Laue diffraction, Journal of Glaciology, 57, 111-120, 2011b.

White, S.: Geological significance of recovery and recrystallization processes in quartz, Tectonophysics, 39, $143-170,1977$. 
The Cryosphere Discuss., doi:10.5194/tc-2016-167, 2016

Manuscript under review for journal The Cryosphere

Published: 11 July 2016

(c) Author(s) 2016. CC-BY 3.0 License.

Table 1: Input properties for the simulations F00, F05 and F20. Remaining input properties according to Llorens et al. (2016, Table 1).

\begin{tabular}{|c|c|c|}
\hline Symbol & Explanation & Input value \\
\hline & Minimum bnode separation & $2.5 \times 10^{-4} \mathrm{~m}$ \\
\hline & Maximum bnode separation & $5.5 \times 10^{-4} \mathrm{~m}$ \\
\hline & Time step per simulation step & $10^{8} \mathrm{~s}$ \\
\hline & $\begin{array}{l}\text { Ratio of time step between VPFFT and } \\
\text { recrystallisation codes }\end{array}$ & 20 \\
\hline & $\begin{array}{l}\text { Number of recrystallisation subloops per one step } \\
\text { of VPFFT within one simulation step }\end{array}$ & 20 \\
\hline & Incremental strain per simulation step & 0.01 \\
\hline$\tau_{\text {basal }} / \tau_{\text {non-basal }}$ & $\begin{array}{l}\text { Ice Ih: } \\
\text { Ratio non-basal / basal glide resistance }\end{array}$ & 20 \\
\hline$\tau_{\text {basal }} / \tau_{s-a i r}$ & $\begin{array}{l}\text { Air: } \\
\text { Ratio ice Ih basal resistance/air flow stress }\end{array}$ & 5000 \\
\hline$M_{\text {ice-ice }}$ & $\begin{array}{l}\text { Intrinsic mobility of ice-ice boundaries } \\
\text { (Nasello et al., 2005) }\end{array}$ & $0.023 \mathrm{~m}^{4} \mathrm{~J}^{-1} \mathrm{~s}^{-1}$ \\
\hline$M_{\text {ice-air }}$ & $\begin{array}{l}\text { Intrinsic mobility of ice-air boundaries } \\
\text { (Roessiger et al., 2014) }\end{array}$ & $0.0023 \mathrm{~m}^{4} \mathrm{~J}^{-1} \mathrm{~s}^{-1}$ \\
\hline$\gamma_{\text {ice-ice }}$ & $\begin{array}{l}\text { Ice-ice interface surface energy } \\
\text { (Ketcham and Hobbs, 1969) }\end{array}$ & $0.065 \mathrm{~J} \mathrm{~m}^{-2}$ \\
\hline \multirow[t]{2}{*}{$\gamma_{\text {ice-air }}$} & $\begin{array}{l}\text { Ice-air interface surface energy } \\
\text { (Roessiger et al., 2014) }\end{array}$ & $0.52 \mathrm{~J} \mathrm{~m}^{-2}$ \\
\hline & $\begin{array}{l}\text { Resulting dihedral angle at ice air triple junctions } \\
\text { (Roessiger et al., 2014) }\end{array}$ & $173^{\circ}$ \\
\hline$\alpha_{\text {hagb }}$ & $\begin{array}{l}\text { Critical misorientation: ice high angle boundary } \\
\text { (Weikusat et al., 2010; 2011) }\end{array}$ & $5^{\circ}$ \\
\hline$c$ & $\begin{array}{l}\text { Area energy or compressibility factor } \\
\text { (10 times the value of Roessiger et al., 2014) }\end{array}$ & 0.1 \\
\hline
\end{tabular}


The Cryosphere Discuss., doi:10.5194/tc-2016-167, 2016

Manuscript under review for journal The Cryosphere

Published: 11 July 2016

(c) Author(s) 2016. CC-BY 3.0 License.

(c) (i)

Table 2: Overview on numerical simulations using crystal visco-plasticity and dynamic recrystallisation (DRX) and only normal grain growth (NGG) simulations. NGG simulations used the same initial microstructures than DRX simulations.

\begin{tabular}{|c|c|c|c|c|c|c|c|}
\hline & $\begin{array}{l}\text { Area } \\
\text { fraction } \\
\text { of air }\end{array}$ & $\begin{array}{l}\text { Initial } \\
\text { number of } \\
\text { ice grains }\end{array}$ & $\begin{array}{l}\text { Final } \\
\text { number of } \\
\text { ice grains } \\
\text { DRX } \\
(N G G)\end{array}$ & $\begin{array}{l}\text { Initial mean } \\
\text { ice grain area } \\
\text { and (standard } \\
\text { deviation) }\end{array}$ & $\begin{array}{l}\text { DRX: } \\
\text { Final mean ice } \\
\text { grain area and } \\
\text { (standard } \\
\text { deviation) }\end{array}$ & $\begin{array}{l}\text { NGG: } \\
\text { Final mean ice } \\
\text { grain area and } \\
\text { (standard } \\
\text { deviation) }\end{array}$ & $\begin{array}{l}\text { Final and } \\
\text { (initial) first } \\
\text { eigenvalue of } \\
\text { CPO }\end{array}$ \\
\hline F00 & $0 \%$ & 3267 & $\begin{array}{l}1631 \\
(1093)\end{array}$ & $\begin{array}{l}6.12 \mathrm{~mm}^{2} \\
\left(3.50 \mathrm{~mm}^{2}\right)\end{array}$ & $\begin{array}{l}12.17 \mathrm{~mm}^{2} \\
\left(12.26 \mathrm{~mm}^{2}\right)\end{array}$ & $\begin{array}{l}18.30 \mathrm{~mm}^{2} \\
\left(13.25 \mathrm{~mm}^{2}\right)\end{array}$ & $\begin{array}{l}0.8032 \\
(0.6692)\end{array}$ \\
\hline F05 & $5 \%$ & 3128 & $\begin{array}{l}1994 \\
(1155)\end{array}$ & $\begin{array}{l}6.07 \mathrm{~mm}^{2} \\
\left(3.43 \mathrm{~mm}^{2}\right)\end{array}$ & $\begin{array}{l}9.44 \mathrm{~mm}^{2} \\
\left(10.87 \mathrm{~mm}^{2}\right)\end{array}$ & $\begin{array}{l}16.43 \mathrm{~mm}^{2} \\
\left(12.34 \mathrm{~mm}^{2}\right)\end{array}$ & $\begin{array}{l}0.7613 \\
(0.6663)\end{array}$ \\
\hline F20 & $20 \%$ & 2654 & $\begin{array}{l}1891 \\
(1265)\end{array}$ & $\begin{array}{l}5.96 \mathrm{~mm}^{2} \\
\left(3.33 \mathrm{~mm}^{2}\right)\end{array}$ & $\begin{array}{l}8.30 \mathrm{~mm}^{2} \\
\left(9.80 \mathrm{~mm}^{2}\right)\end{array}$ & $\begin{array}{l}12.53 \mathrm{~mm}^{2} \\
\left(10.52 \mathrm{~mm}^{2}\right)\end{array}$ & $\begin{array}{l}0.6933 \\
(0.6649)\end{array}$ \\
\hline
\end{tabular}


The Cryosphere Discuss., doi:10.5194/tc-2016-167, 2016

Manuscript under review for journal The Cryosphere

Published: 11 July 2016

(c) Author(s) 2016. CC-BY 3.0 License.
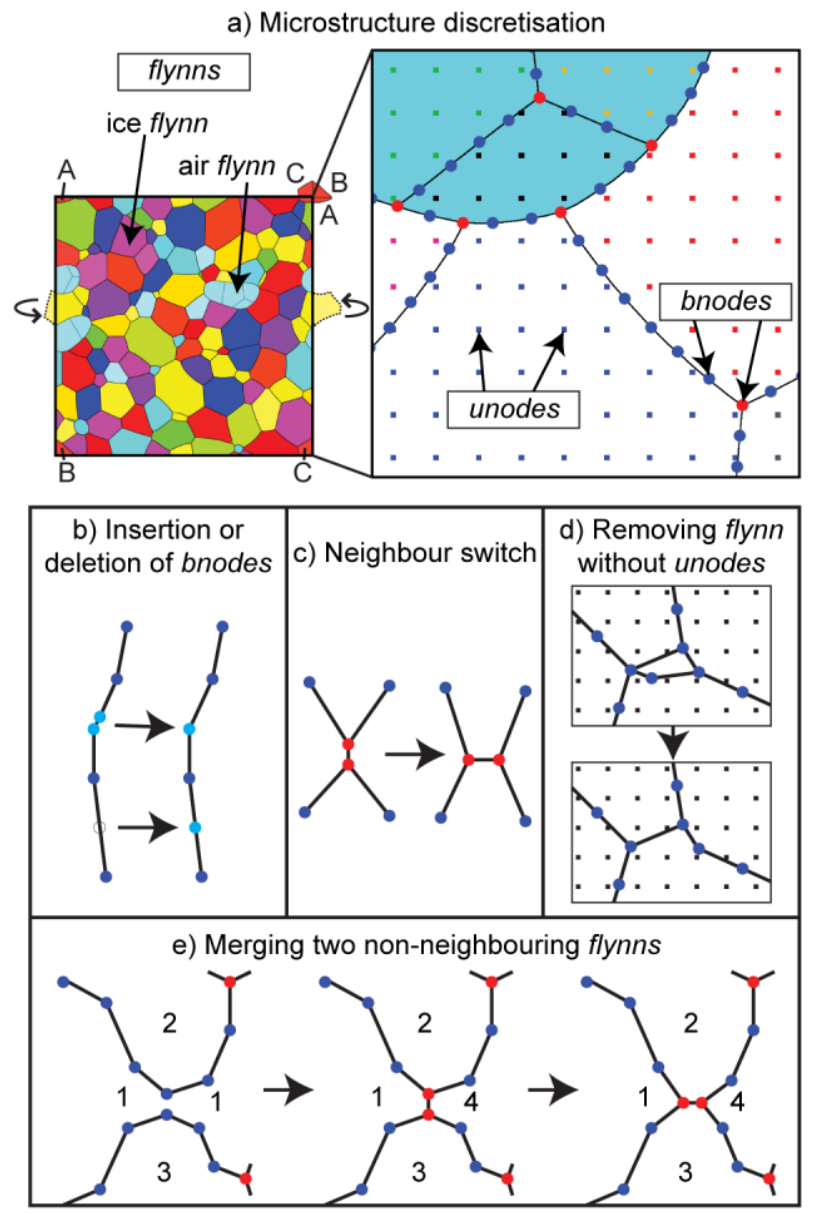

Figure 1: Microstructure discretisation in Elle. (a) A contiguous set of polygons (flynns) is composed of boundary nodes (bnodes) and has periodic boundaries. An additional grid of unconnected nodes (unodes) is superimposed on flynns and bnodes to store intracrystalline properties, state variables and track deformation. (b-e) Topological checks performed to keeping topological restrictions in Elle. Checks (b), (c) and (e) are based on minimum and maximum bnode separations. Check (d) removes extremely small flynns that contain no undoes or have areas smaller than the area enclosed by four neighbouring unodes by merging them to a neighbour of the same phase. 
The Cryosphere Discuss., doi:10.5194/tc-2016-167, 2016

Manuscript under review for journal The Cryosphere

Published: 11 July 2016

(c) Author(s) 2016. CC-BY 3.0 License.

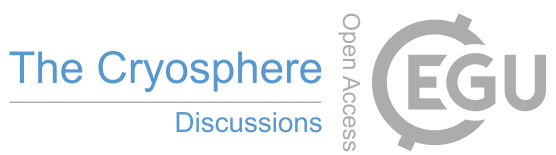

(a)

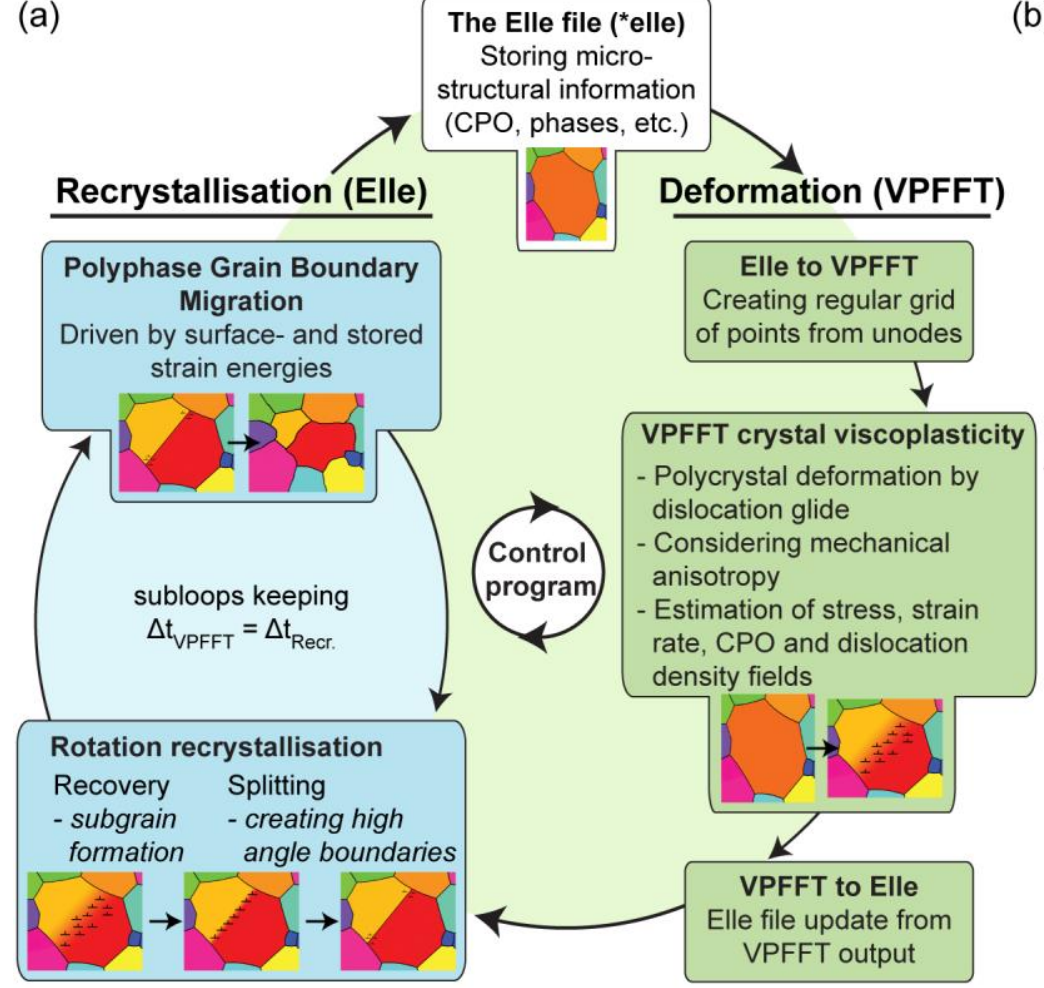

(b)

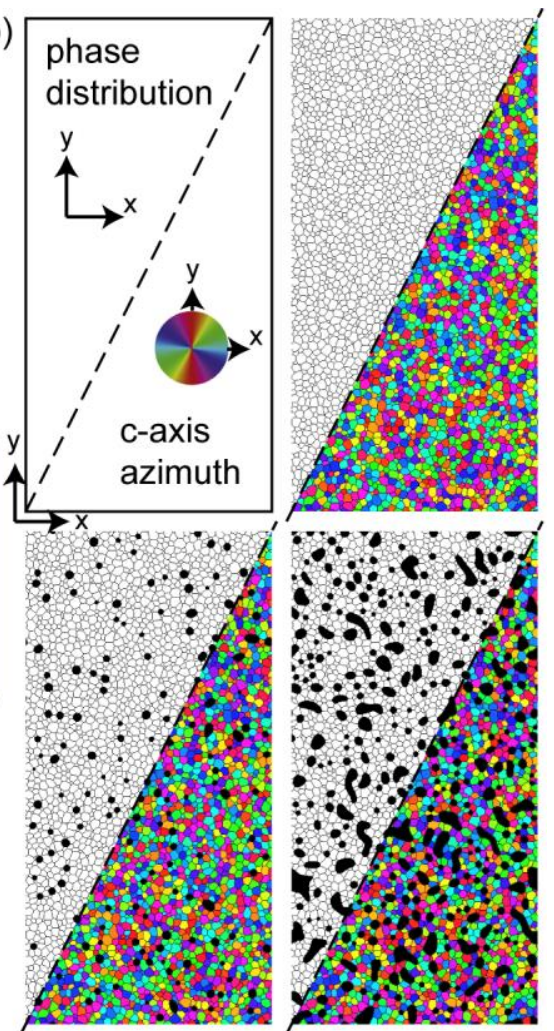

Figure 2: (a) Multi-process modelling by operator splitting is achieved by successively running individual process modules. One step of deformation by VPFFT code is followed by five subloops (with shorter time steps) of recrystallisation, each comprising four steps of recovery and grain-boundary migration, to keep a constant time step for all combined processes. (b) Initial 10x20 cm microstructures with foam textures containing $0 \%, 5 \%$ and $20 \%$ of air and with an initially random crystallographic fabric. Upper left half shows grain boundary network, lower right the lattice orientations. 
The Cryosphere Discuss., doi:10.5194/tc-2016-167, 2016

Manuscript under review for journal The Cryosphere

Published: 11 July 2016

(c) Author(s) 2016. CC-BY 3.0 License.

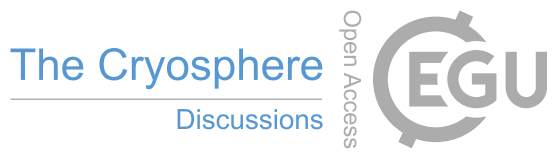

(c) (i)

(a) Passive marker grids

| | | | initially vertical lines

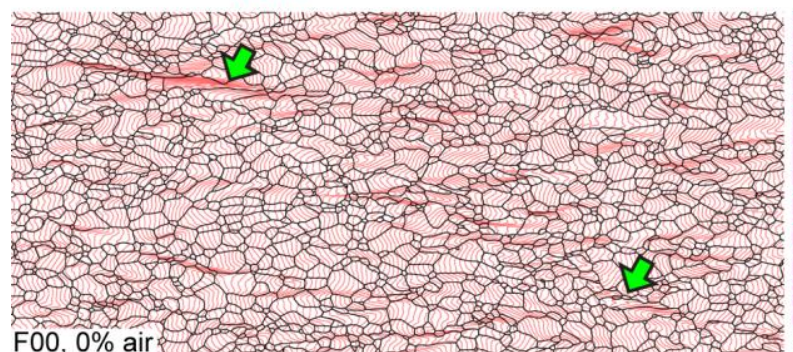

$\mathrm{FO0}, 0 \%$ air \& $25, \mathrm{~s}$ है
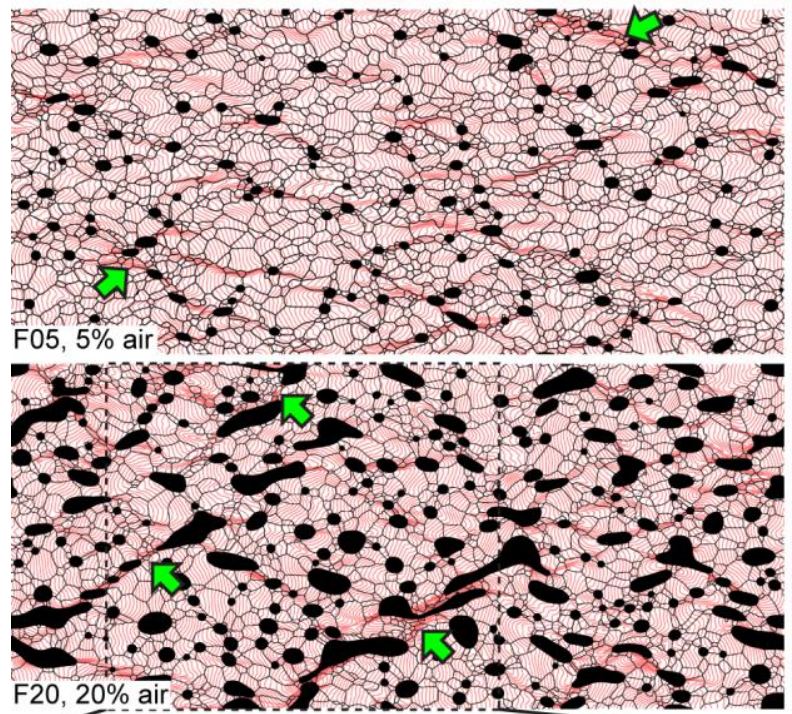

F20, 20\% air es 1 .

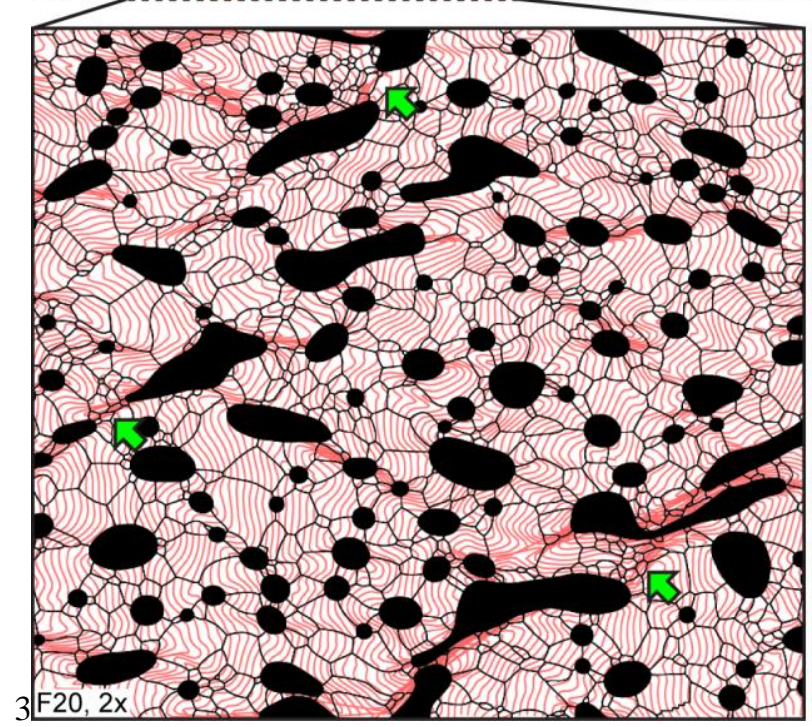

(b) Instantaneous normalised von Mises strain rates
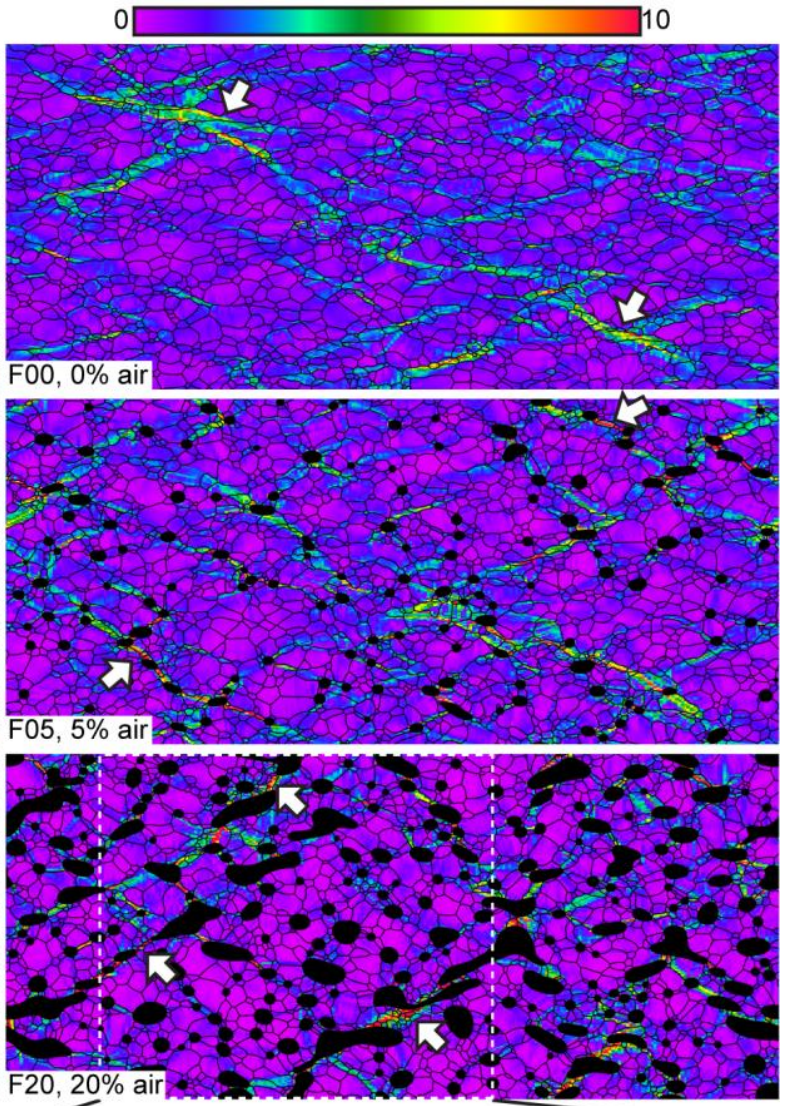

Figure 3: Overview of modelling results at last time step at $53 \%$ vertical shortening under pure shear conditions. (a) Grain boundary network superimposed on passive marker grid of initially vertical parallel lines to show the finite strain distribution. (b) The same microstructures superimposed on the map of instantaneous strain rates expressed as von Mises strain rates normalized to the bulk value. Arrows in both images indicate zones of marked strain localisation. Air inclusions are displayed in black. 
The Cryosphere Discuss., doi:10.5194/tc-2016-167, 2016

Manuscript under review for journal The Cryosphere

Published: 11 July 2016

(c) Author(s) 2016. CC-BY 3.0 License.

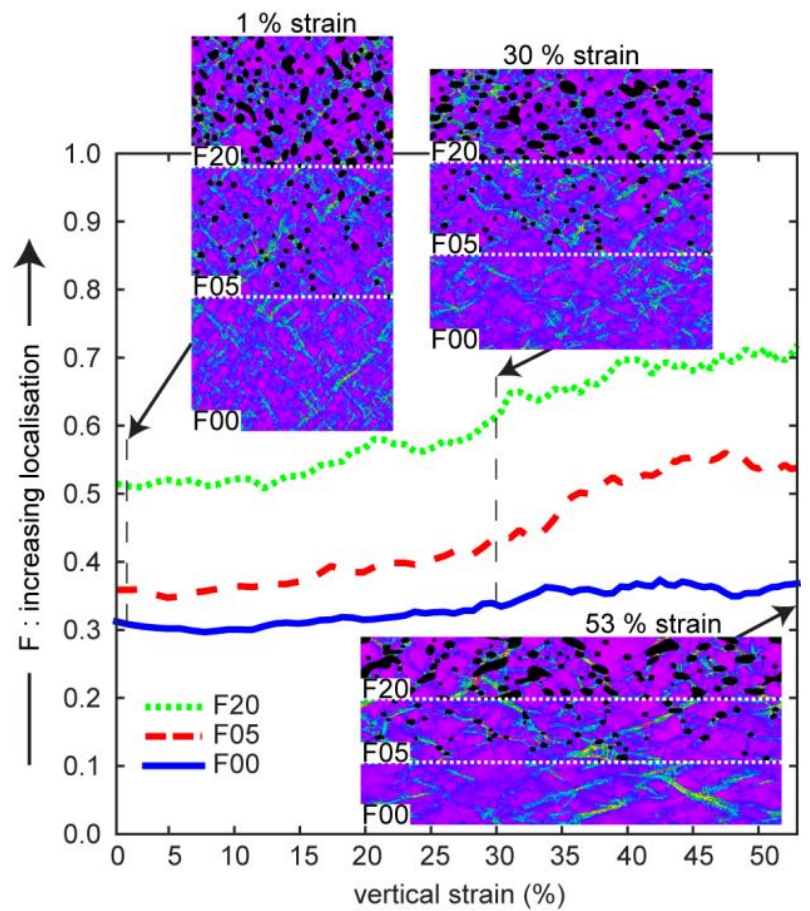

Figure 4: Evolution of localisation factors (F) with strain quantifying strain localisation in the microstructures for all simulations. A factor of 0 represents homogeneous deformation, the factor increases towards one with increased strain-rate heterogeneity and localisation. The normalized von Mises strain rate maps at $1 \%, 30 \%$ and $53 \%$ vertical strain are shown for reference. The maps 5 are subdivided to show results of simulation F20 in the upper third, of F05 in the middle and F00 in the lower third part of the model box. They illustrate strain localisation at different stages of the simulation. 
The Cryosphere Discuss., doi:10.5194/tc-2016-167, 2016

Manuscript under review for journal The Cryosphere

Published: 11 July 2016

(c) Author(s) 2016. CC-BY 3.0 License.

The Cryosphere

(c) (i)

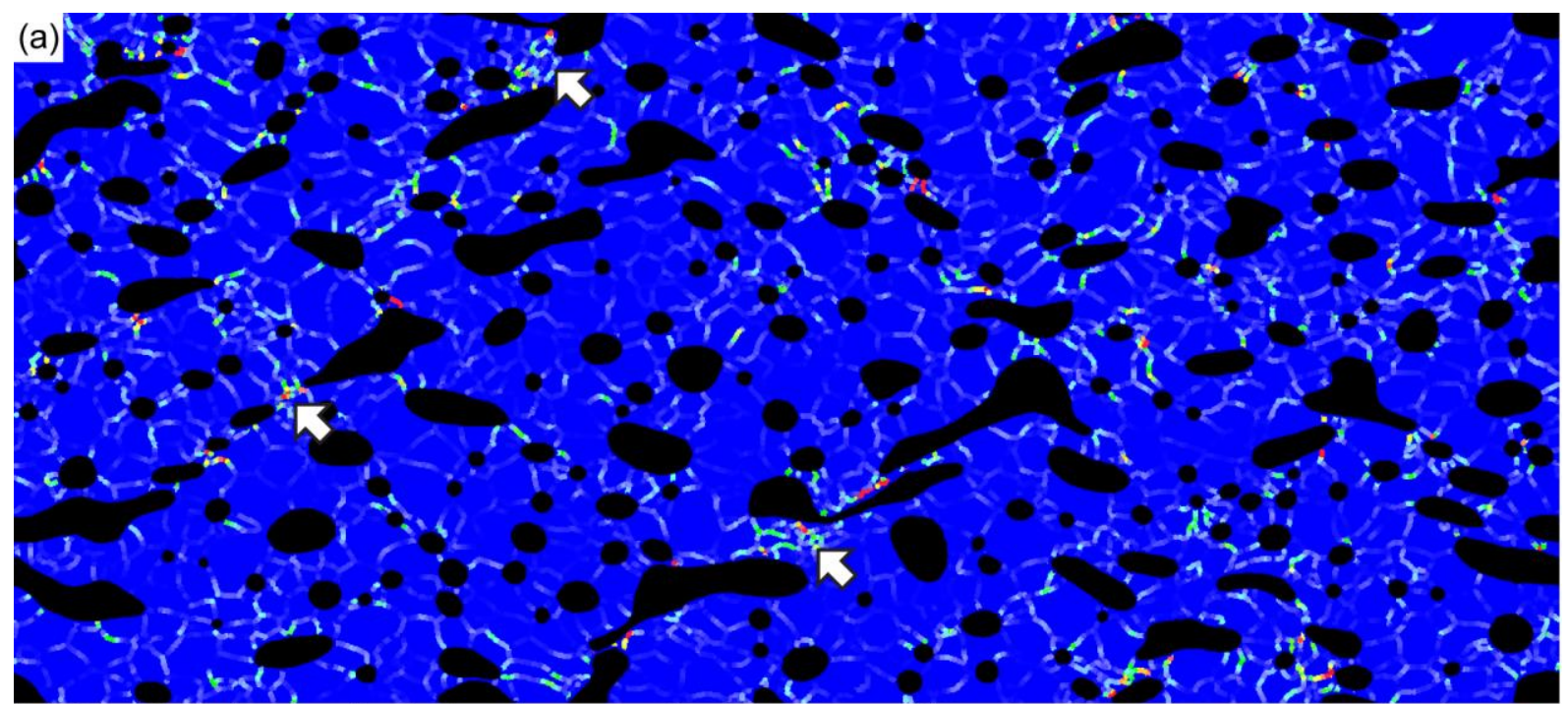

(a) Stored strain energies in bnodes normalised to mean surface energy
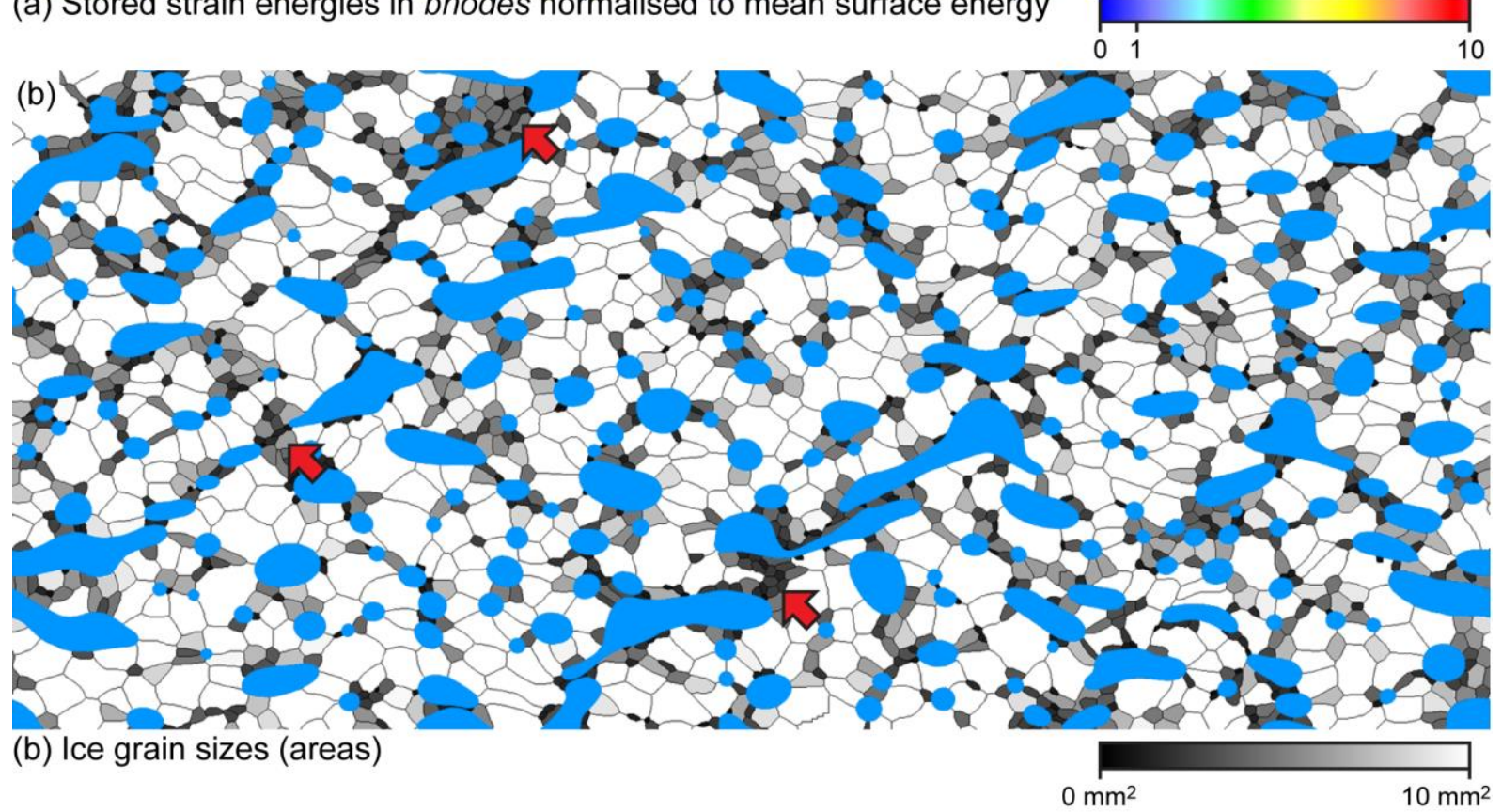

Figure 5: Details of results of simulation F20 at 53\% vertical shortening: (a) Boundary nodes colour coded according to the proportion of strain-induced boundary migration. Air inclusions are plotted in black since they do not contribute to strain induced boundary migration. (b) Microstructure colour-coded according to the areas of ice grains, with air inclusions displayed in blue.

Smallest grains appear grey to black. Arrows in both images indicate zones of marked strain localisation. 
The Cryosphere Discuss., doi:10.5194/tc-2016-167, 2016

Manuscript under review for journal The Cryosphere

Published: 11 July 2016

(c) Author(s) 2016. CC-BY 3.0 License.
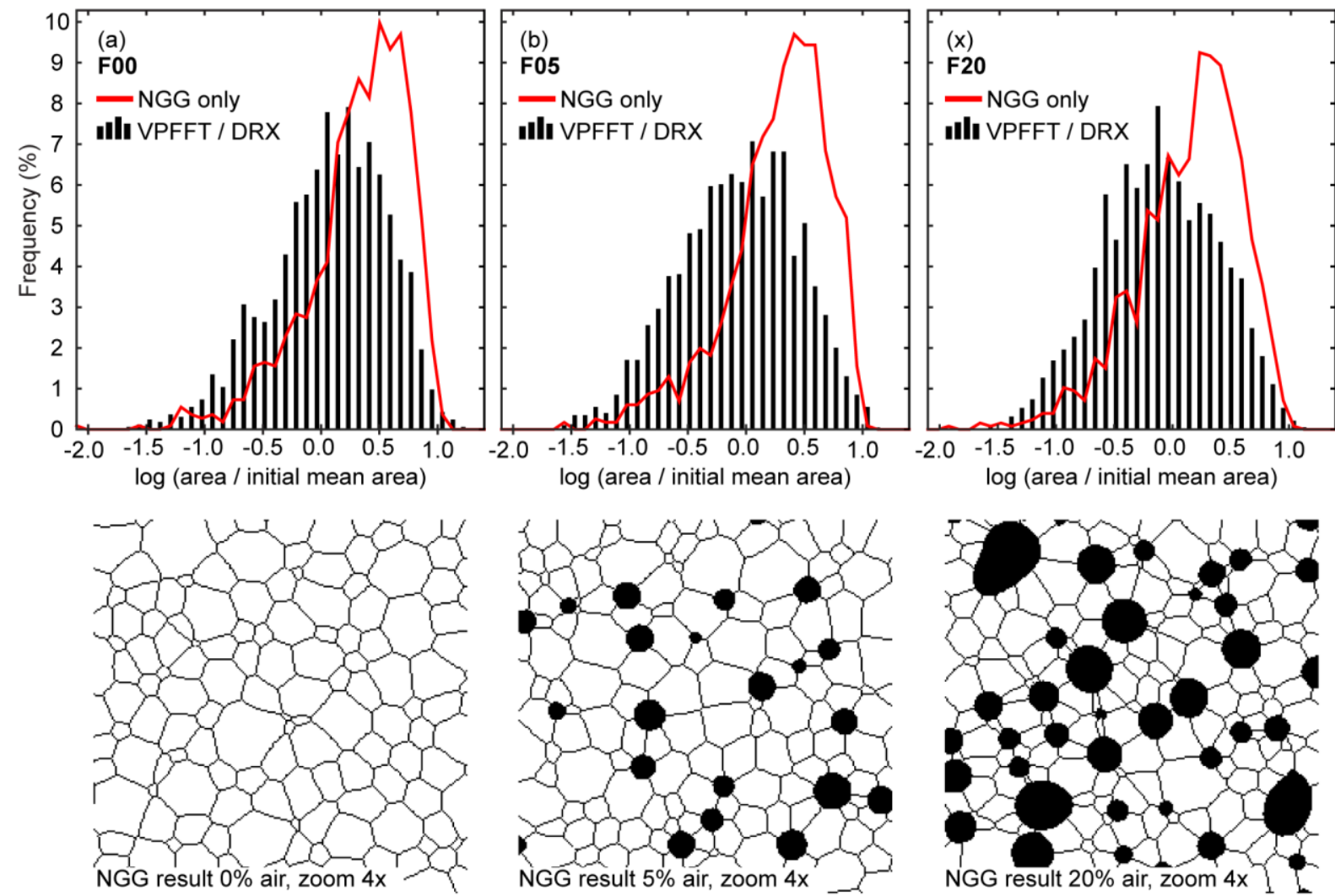

Figure 6: Comparison of ice grain area histograms of the last simulation step of simulations (a) F00, (b) F05 and (c) F20. Normal grain growth (NGG) simulations using F00, F05 and F20 input models are displayed with the respective deformation and dynamic recrystallisation (VPFFT / DRX) simulation results. Areas were normalized to initial mean values that plot at a value of 0.0 on $x$ axis. For reference, a fourfold zoom in the resulting microstructures from NGG simulations is displayed below the histograms. 
The Cryosphere Discuss., doi:10.5194/tc-2016-167, 2016 Manuscript under review for journal The Cryosphere

Published: 11 July 2016

(c) Author(s) 2016. CC-BY 3.0 License.

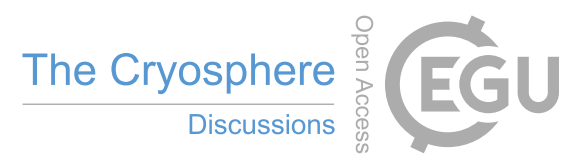

(c) (i)

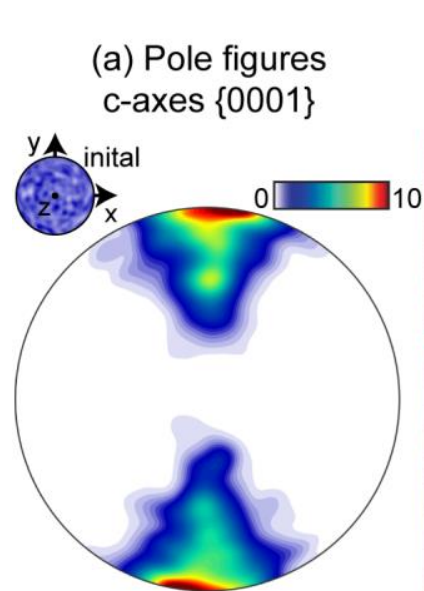

F00, 1st eigenvalue: 0.8032

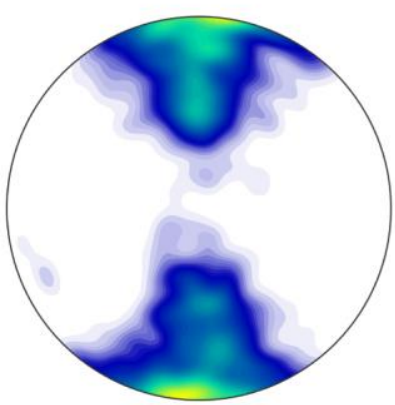

F05, 1st eigenvalue: 0.7613
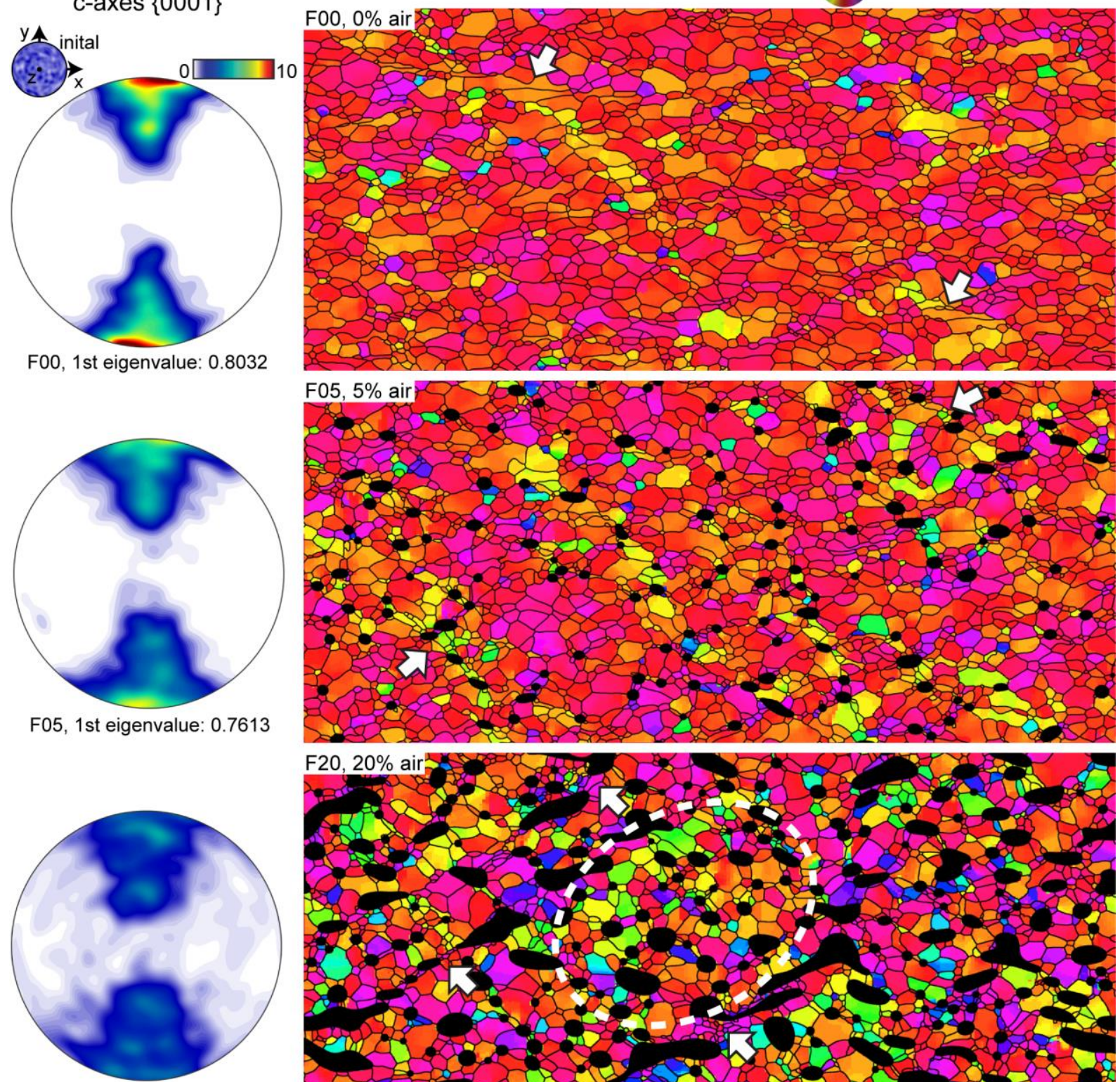

F20, 1st eigenvalue: 0.6933

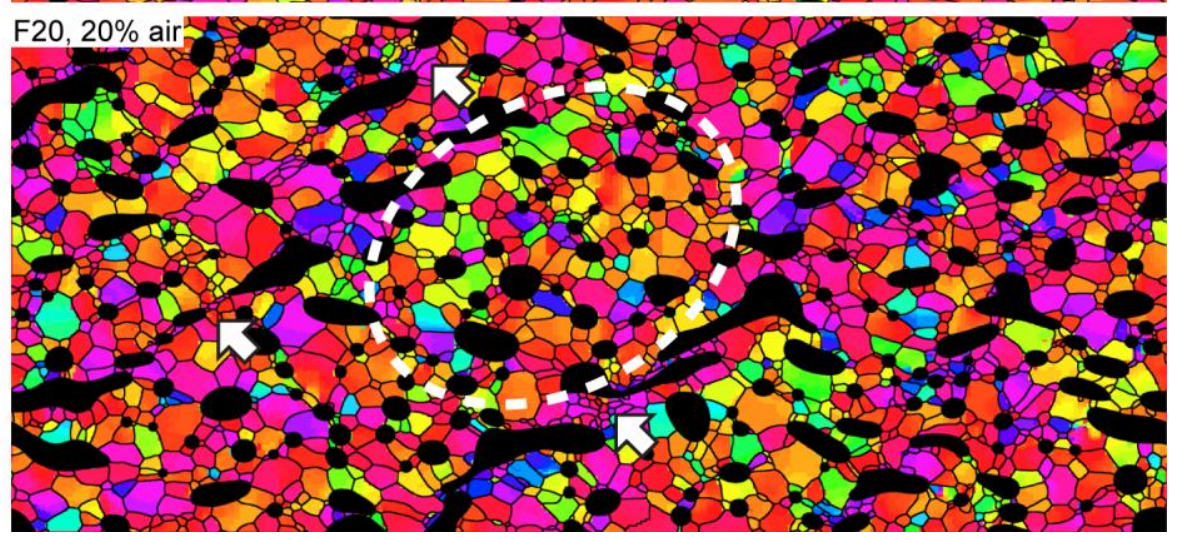

Figure 7: Overview of c-axis orientations at $53 \%$ vertical shortening for all simulations. (a) Pole figures with the projection plane parallel to the $x$ - $y$ plane of the 2D model. (b) Maps of c-axis azimuth distributions. Air inclusions are shown in black. White arrows in both images indicate zones of marked strain localisation. Dotted white line indicates zone of low strain where more random 5 crystallographic orientations are preserved. 
The Cryosphere Discuss., doi:10.5194/tc-2016-167, 2016

Manuscript under review for journal The Cryosphere

Published: 11 July 2016

(c) Author(s) 2016. CC-BY 3.0 License.
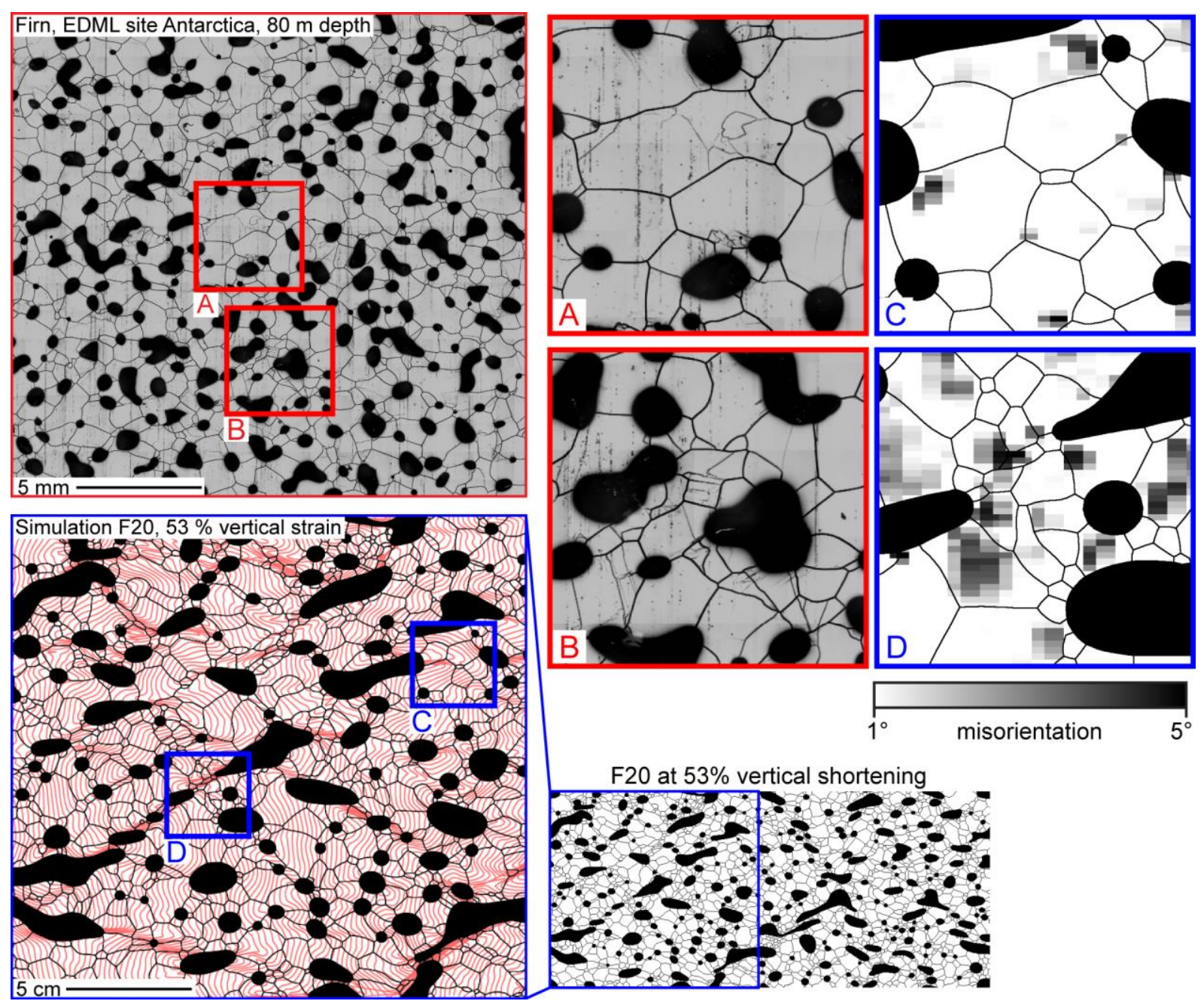

Figure 8: Comparison of simulation results of $\mathbf{F 2 0}$ at $53 \%$ vertical shortening with firn microstructure mapping images from the EDML ice core site at $80 \mathrm{~m}$ depth (courtesy of Sepp Kipfstuhl). The detail areas A-D illustrate different microstructures occurring in relation to strain localisation. Grain boundaries stand out as black lines and subgrain boundaries are visible as fainter grey 5 lines. Vertical stripes appearing in the overview image are related to the sample polishing technique and not reflecting any microstructural property. Greyscales $\mathrm{C}$ and $\mathrm{D}$ indicate local average misorientations as stored in unodes and therefore appear blurred due to the strong magnification. 